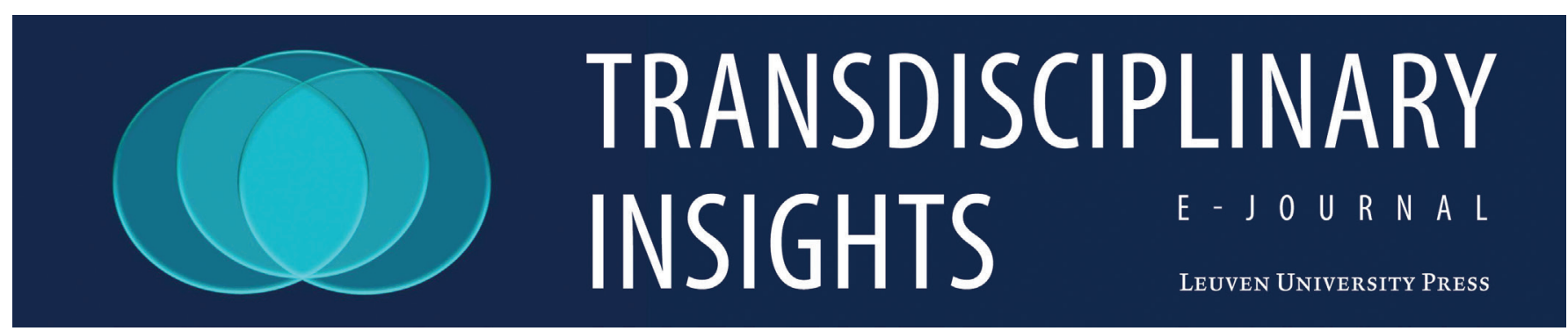

\title{
Student Team Sustainability Research Projects as an Approach to Education for Sustainability at the University Level
}

\section{G. Ceulemans, ${ }^{1, \$}$ B. Dewulf, 2,* J. D’hollander, 3, * F. M. Fedorowicz,, ${ }^{4, *}$ J. Kempeneers, ${ }^{5, *}$ \\ K. Muylaert, ${ }^{6}$ E. Obad Aghandum, ${ }^{7, *}$ \\ D. Vandamme, ${ }^{6,8}$ T. Peirs, ${ }^{9, *}$ E. Philips, ${ }^{9, *}$ \\ V. Smeesters, ${ }^{10, *}$ F. Van Hooreweghe, ${ }^{11, *}$ \\ H. Vermeulen, ${ }^{12, *}$ V. Verswijvel, ${ }^{13, *}$}

F. Volckaert, ${ }^{14 *}$ P.-J. Vroom, ${ }^{9, *}$ and N. Severijns ${ }^{15}$

${ }^{1} \mathrm{KU}$ Leuven, Department of Chemistry \& Specific Teacher Education Centre of the Natural Sciences (option Chemistry), Leuven, Celestijnenlaan 200C box 2406, B-3001 Leuven (Heverlee), Belgium.

${ }^{2} \mathrm{KU}$ Leuven, Master's student Chemistry, Leuven, Belgium;

${ }^{3} \mathrm{KU}$ Leuven, Master's student Biology, Leuven, Belgium;

${ }^{4} \mathrm{KU}$ Leuven, Master's student Chemistry, Leuven, Belgium;

${ }^{5} \mathrm{KU}$ Leuven, Master's student of the Specific Teacher Education of the Natural Sciences, Leuven, Belgium;

${ }^{6} \mathrm{KU}$ Leuven, KULAK Kortrijk Campus, Department of Biology, Kortrijk, Belgium;

${ }^{7} \mathrm{KU}$ Leuven, Master's student Geology, Leuven, Belgium;

${ }^{8}$ UHasselt - Hasselt University, Institute for Materials Research (IMO-IMOMEC), Research Group of Applied and Analytical Chemistry, Agoralaan-gebouw D, B-3590 Diepenbeek, Belgium

${ }^{9} \mathrm{KU}$ Leuven, Master's student Geography, Leuven, Belgium;
${ }^{10} \mathrm{KU}$ Leuven, Master's student Mathematics, Leuven, Belgium;

${ }^{11} \mathrm{KU}$ Leuven, Master's student Biology, Leuven, Belgium;

${ }^{12} \mathrm{KU}$ Leuven, Master's student Statistics, Leuven, Belgium;

${ }^{13} \mathrm{KU}$ Leuven, Master's student Geology, Leuven, Belgium;

${ }^{14} \mathrm{KU}$ Leuven, Department of Biology, Leuven, Belgium; ${ }^{15} \mathrm{KU}$ Leuven, Department of Physics and Astronomy, Leuven, Belgium;

\$Email: griet.ceulemans@kuleuven.be

*These authors contributed equally to this work

\section{Abstract}

At this moment about 7.6 billion people inhabit the earth (Worldpopulation clock 2018). A sustainability revolution is necessary (WCED 1987, UNCED 1992, Rockström 2009) to avoid this huge population in striving for a luxury life depleting the resources of the planet. There are also important social issues that need to be resolved (Raworth 2017). It has been argued that even a real cultural shift is needed (Kagan 2010).

This revolution can be started in education (UN 2003). The decade of education for sustainable development 
(UNESCO 2014a) ran from 2005 till 2014. It is being carried further in the Global Action Program (UNESCO 2014b). At the University of Leuven, the 'Science and Sustainability' course is a stand-alone elective course of 6 credits that specifically aims to provide master's students in the natural sciences with education for (the benefit of) sustainability action (Ceulemans \& Severijns 2018a and 2018b). Last year (2016-2017), the course ran for the first time and insight was gained in the competences that master's level students hold for sustainability. Based on this experience, stronger emphasis was placed in the second year (2017-2018) on providing, and making students use, tools to approach sustainability issues. Specific attention was directed toward allowing students to get acquainted with systems thinking and deal with inter- and transdisciplinary issues by approaching problems from a multi-stakeholder point of view. The sustainability reports the student teams compiled therefore necessarily included a representation of the system map they compiled to get a grip on the sustainability issue. Also a stakeholder map needed to be drawn.

Near the end of the course it became apparent that students had difficulty in deviating from the Western interpretation of sustainability, where ecological criteria strongly dominate and ecological responsible behavior is pretended to be adequate to drive the transformation for true sustainability. However, it is in the socio-political and socio-cultural dimensions that the value-laden component of sustainability is really found. Several team-tailored feedback and discussion sessions were therefore organized to make students at least consider a slightly broader view on sustainability.

Three student reports of projects that were carried out within this framework are presented in the appendices to this abstract. Students were asked to focus in their reports specifically on the broader sustainability related issues. Technical and exact-scientific information related to their project topic was preferably included in an addendum. Sustainability dimensions on which a focus was laid (e.g. Social, Cultural, Politics, Economics, Communications) varied among the projects, being largely dependent on the topic addressed and in part also on the major stakeholders.

\section{Key words}

Education, sustainability, socio-cultural dimension, socio-political dimension, university, projects

\section{References}

Ceulemans G. \& Severijns S. 2018a, Challenges and benefits of on-campus and off-campus sustainability research projects as an approach to education for sustainability, Universities in University Campuses, Eds Walter Leal Filho, Ugo Bardi, World Sustainability Series, Springer (accepted)

Ceulemans G. \& Severijns S. 2018b, A pragmatic framework for setting up transdisciplinary sustainability research on-campus that can make a difference, Universities in University Campuses, Eds Walter Leal Filho, Ugo Bardi, World Sustainability Series, Springer (accepted)

Kagan S. 2010, Cultures of sustainability and the aesthetics of the pattern that connects, Futures 42, 1094-1101

Raworth K. 2017, A Doughnut for the Anthropocene: humanity's compass in the 21st century, The Lancet Planetary Health, 2017, 1(2), e48-e49

Rockström J. et al. 2009, A safe operating space for humanity, Nature 461, 472-475 http://www.academia. edu/2547695/A_safe_operating_space_for_ humanity

UN 2003. Resolution adopted by the General Assembly - 57/254. United Nations Decade of Education for Sustainable Development. http://www.un-documents.net/a57r254.htm (last accessed September 17, 2018)

UNCED 1992. United Nations Conference on Environment \& Development - Rio de Janerio, Brazil, 3-14 June 1992 - AGENDA 21 http://sustainabledevelopment.un. org/content/documents/Agenda21.pdf (last accessed September 17, 2018)

UNESCO 2014a. Shaping the future we want, UN Decade of Education for Sustainable Development (2005-2014) FINAL REPORT http://unesdoc.unesco. org/images/0023/002301/230171e.pdf (last accessed September 17, 2018)

UNESCO 2014b, Roadmap for Implementing the Global Action Programme on Education for Sustainable Development http://unesdoc.unesco.org/images/ 0023/002305/230514e.pdf (last accessed September $17,2018)$

WCED 1987. Report of the World Commission on Environment and Development: Our Common Future (Brundtland report). http://www.un-documents.net/ our-common-future.pdf

World population clock 2018. http://www.census.gov/ popclock/ (last accessed September 17, 2018) 


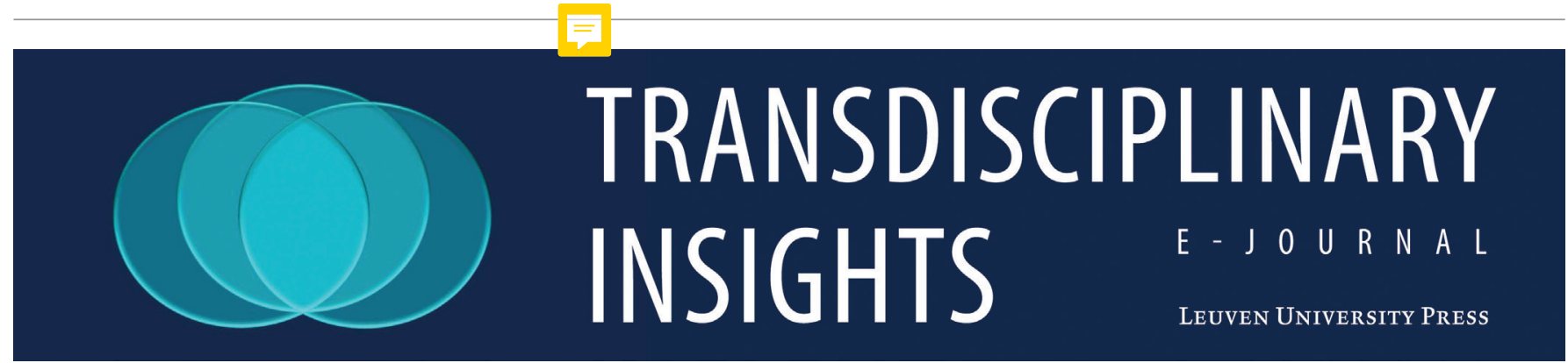

\section{Student Team Sustainability Research Projects as an Approach to Education for Sustainability at the University Level}

\section{Biofuels in aviation: solution or a myth? - A European perspective}

\section{J. D'hollander, ${ }^{1, *}$ F. M. Fedorowicz, ${ }^{2, *}$}

J. Kempeneers, ${ }^{3, *}$ K. Muylaert, ${ }^{4}$

D. Vandamme, ${ }^{4,5}$ N. Severijns,${ }^{6}$ and

G. Ceulemans ${ }^{7}$

${ }^{1} \mathrm{KU}$ Leuven, Master's student Biology, Leuven, Belgium;

${ }^{2} \mathrm{KU}$ Leuven, Master's student Chemistry, Leuven, Belgium;

${ }^{3} \mathrm{KU}$ Leuven, Master's student of the Specific Teacher Education of the Natural Sciences, Leuven, Belgium;

${ }^{4} \mathrm{KU}$ Leuven, KULAK Kortrijk Campus, Department of Biology, Kortrijk, Belgium;

${ }^{5}$ UHasselt - Hasselt University, Institute for Materials Research (IMO-IMOMEC), Research Group of Applied and Analytical Chemistry, Agoralaan-gebouw D, B-3590 Diepenbeek, Belgium

${ }^{6} \mathrm{KU}$ Leuven, Department of Physics and Astronomy, Leuven, Belgium;

${ }^{7} \mathrm{KU}$ Leuven, Department of Chemistry \& Specific Teacher Education Centre of the Natural Sciences (option Chemistry), Leuven, Belgium.

*These authors contributed equally to this work.

\section{Summary}

The impact of the aviation industry on global carbon emission is important as it represents by itself $2 \%$ of global $\mathrm{CO}_{2}$ emissions, but concrete actions to make the industry more sustainable do not yet result in a visible effect. Indeed, despite the recent advances in technology concerning bio jet fuels, investors are hesitant. This is mostly due to inconsistent policy from the EU. The airline companies at the same time are trying to undermine most EU policies that enforce change, fearing it will affect their prices and create an economic disadvantage. The traveler also has an ethical responsibility and a cultural change to look at transportation differently might be needed.

\section{Introduction}

Aviation is a fast-growing industry (1). Revenue Passenger Kilometers $\left(\mathrm{RPK}^{1}\right.$ ) values show that people have never traveled as much by plane as they do right now (2). In December 2017, IATA proudly announced that the global RPK values had increased by $7.6 \%$ compared to 2016 levels. Expressed in number of passengers carried, this comes down to a record total of 4.1 billion passengers transported by air in 2017 (3), an increase by a factor of four compared to 1990 levels. And the aviation industry is expected to grow even further. Predictions show an annual growth rate of

\footnotetext{
${ }^{1}$ Revenue passenger kilometers (RPK) is an airline metric that indicates the number of kilometers travelled by paying passengers. One RPK amounts to the transportation of one passenger over the distance of one $\mathrm{km}$.
} 
$3.6 \%$ for the future, meaning the number of air passengers will double over the next 20 years. The biggest driver of this growth is expected to be the AsiaPacific region, whereas over the past decades the aviation market has been mostly dominated by Europe and the United States (4).

This growth has outpaced efficiency gains, resulting in a worldwide consumption of 200 million tons of kerosene per year, so that the aviation industry is now responsible for $2 \%$ of the total global human greenhouse gas emissions $(5,6)$. With an expected continuous growth rate of $3.6 \%$ per year (4), energy use and associated greenhouse gas emissions will continue to increase as well (7). If the fuel consumption and greenhouse gas emissions in other sectors were to grow at the same rate as in the aviation industry, $\mathrm{CO}_{2}$ emissions worldwide would be multiplied by a factor of six by 2050. Taking the expected efficiency gains into account, it is predicted that fuel consumption would 'only' triple by 2050 (8).

This is in sharp contrast to the ambitious target of the aviation industry to reduce $\mathrm{CO}_{2}$ emissions. The International Air Transport Association (IATA) announced in 2009 that it is committed to achieving carbon neutral growth from 2020 onwards, and a 50\% reduction in carbon emissions over 2005 levels by 2050 (9). IATA is determined to achieve these goals by improved technology, more efficient aircraft operations, and infrastructure improvement. In order to achieve these goals, IATA identifies sustainable aviation fuels as one of the key elements because they produce $80 \%$ less $\mathrm{CO}_{2}$ compared to conventional jet fuels over the total lifecycle (9). Biofuels can be produced from plants, or from different types of waste (e.g. from agriculture, industry or domestic) if this has a biological origin. Renewable biofuels generally involve contemporary carbon fixation, as occurs in plants or microalgae via photosynthesis.

The use of sustainable aviation fuels sounds promising so far. However, some caveats have to be made. First of all, the use of sustainable aviation fuels does not directly imply a zero-net emission. The production of the feedstock can have an environmental impact as well, and this should not be ignored. Second, sustainable aviation fuels need to meet criteria such as a high energy density and strict safety standards. Next, sustainable aviation fuels are at present produced on only a small scale. In order to make large-scale production feasible technological improvements are required. And, finally, the production of sustainable aviation fuels comes at a high cost, making them currently not competitive with fossil fuels (10). Nevertheless, apart from these obstacles, the use of sustainable aviation fuels is technically viable. The first test flight on sustainable aviation fuels has taken place. In November 2017, the number of flights running on a sustainable aviation fuel blend reached 100,000. However, this is only a small fraction of the total number, as worldwide about 100,000 flights take place every day (11)! To facilitate the use of sustainable aviation fuels, the European Commission suggests an appropriate set of supporting policies (8). The importance of policy is also acknowledged in a feasibility study of biofuels in Australia (12).

Today, almost 10 years after IATA announced its targets for carbon emission reductions, sustainable aviation fuels are available on only a small scale and can be used only in blends with fossil fuels. In terms of logistics, the use of sustainable aviation fuels is not even mentioned by airports, such as e.g. in the 2017 Sustainability Report of Brussels Airport, the national airport of Belgium (13). A possible explanation is the lack of policy and incentives from European Union (EU) policy makers. According to the European Commission (EC), one of the criteria for successfully implementing sustainable aviation fuels is an appropriate set of supporting policies, and up until today no strict legislation regarding the use of sustainable aviation fuels has yet been defined (8).

This paper investigates the current situation regarding sustainable aviation fuels and the problems encountered by stakeholders when it comes to implementing sustainable aviation fuels. In view of the time constraints related to the fact that this research was performed as part of a master's level course dealing with sustainability, it was decided to focus mainly on the lack of policy and the reasons behind it and on current incentives, and thereby limit the stakeholders to the nearby Brussels Airport and the European Commission. Information was obtained from reports and other documents.

\section{Analysis}

Brussels Airport (BA) recently published an environmental report for the year 2017. What is understood by the term sustainability relates more closely to a certain energy (and therefore economic) efficiency. 
The 62-page report does not mention bio jet fuel even once, while media and public opinion claim that the $\mathrm{CO}_{2}$ emissions from the aviation industry and the decreasing cost of travelling by airplane are the elephant in the room. It was, however, found that it is not BA but the airline companies themselves that provide the fuel for their aircraft. The companies make deals with fuel suppliers to use their fuel and manage the fuel pumps they install at an airport. Smaller airlines can then pay for the service of using the bigger companies' fuel. There are, however, some airports (in e.g. Sweden, The Netherlands, and Canada) and a number of airline companies (e.g. KLM, Finnair, Air Canada, South African, and Singapore Airlines) that have joined SkyNRG ${ }^{2}$ to make sustainable aviation fuels the new global standard (14). Apart from that, the Air Transport Action Group (ATAG) has issued statements that future carbon-neutral growth of the aviation sector lies in the usage of low-carbon emission fuel with bio-based components (15).

The European Commission (EC) has shown initiative to encourage the use of bio jet fuel in the aviation industry through the European Advanced Biofuels Flightpath Directive (16) and the European Trading Scheme (ETS) for carbon pricing, but taking farreaching decisions was hampered by the fact that not everyone was convinced of the environmental benefit that would potentially be gained by the use of bio jet fuel. The energy think tank 'Insight_E' which is informing the European Commission recently argued that also considering indirect land use effects might show a strong reduction in environmental effectiveness of biofuels (17). The effectiveness of the carbon pricing trading scheme is also a subject of debate due to the huge drop in price of the carbon stocks (17). The lack of a strong unidirectional policy from the EC has created uncertainty on the European biofuel market, and because of this investors are more hesitant to support biofuel development (17).

\footnotetext{
${ }^{2}$ SkyNRG is a Dutch company which makes it its mission to lower the hurdles of supplying airlines with sustainable aviation fuels and aims at making such fuels the new global standard. An important observation is that its mission focuses on the supply of sustainable aviation without the complications of deforestation or displacement of food crops. So far, the company has had a rather impressive track record and SAF flight map with recent development in the sustainable aviation fuel sector. To find out more about the mission and statements of the company one is advised to visit their website, http://skynrg.com/.
}

Fortunately, there are many projects taking place which are not per se regulated by policy makers or by large companies. Even if those companies at present do not (yet) have the potential to reach the capacities needed, being pioneers they do serve as a level arm for further development and activities in this sector. One of these is the bio-chemical company Proviron, situated in Ostend, Belgium. This company produces prime microalgae which have the potential to produce bio jet fuel. The production of bio jet fuel from microalgae can be seen as a chance to counter the large emissions of the current fossil fuel usage within the aviation industry. Many advantages and disadvantages can be found for the use of these wild algae to produce the fuel of the future, such as the energy conversion from sunlight to oil, without much external effort, but at the same time land and water use can be factors that determine the efficiency of such microalgae plants (7). The benefit that microalgae have in comparison to firstor second-generation bio fuels is that they can be grown in areas that are otherwise unsuitable for anything else. They do not require the use of fertile soils that could otherwise be used for agriculture, but at the moment the systems are very vulnerable to collapse by disease or pollution. Not to forget the fact that the microalgae actually use $\mathrm{CO}_{2}$ to grow, and thus extract $\mathrm{CO}_{2}$ from the atmosphere.

There are certain observations that can be made as well regarding the economic situation within the industry. In 2012 the aviation industry made a profit of 7.6 billion US dollar(18). As stated before by IATA, the aviation sector is constantly growing with projections being made until 2031. By that year, there will be a demand for 28,500 new-build passenger aircraft as well as freighters. This demand will mostly arise from Asia, South America, and Africa; however, the mostly mature markets of North America and Europe will continue growing as well (19). An interesting observation is that this growth in the aviation industry is seen as a durable solution for the current economic woes. Alexandre de Juniac, CEO at IATA, states that the enforcement of policies that hold back this growth in the aviation sector could raise barriers for trade rather than making it easier. Slower growth of the industry would result in a 'mere' 5.8 billion passengers by 2035 instead of the projected 7.2 billion (20). This easily shows that the current priorities at organizations such as IATA, which represents 235 airlines comprising $83 \%$ of total air traffic, lie in economic 
development rather than sustainable development as a whole.

The importance of transdisciplinarity can easily be understood by the above analysis, highlighting the importance of policy making and politics, economics, and the environmental challenge of finding a fuel source that could be considered a sustainable alternative to fossil fuels. The systems map (Fig. 1) highlights this transdisciplinarity even more. Note that also playing an important role in this are research centers such as e.g. the Joint Research Center of the European Commission in Karlsruhe, the University of Wageningen's Food \& Biobased Research Center (The Netherlands), the Biofuel Research Center at Edinburgh Napier University (UK), the Department of Energy BioEnergy Science Center in Oak Ridge (USA), the Biofuels Research Laboratory at Cornell University (USA), and many others.

\section{Systems map}

The systems map focusses on two concepts that have been discussed thoroughly in this report so far, i.e. sustainable aviation fuels and fossil fuels. It is easily understood that sustainable aviation fuels and fossil fuels are non-complementary and the usage of one will have a negative impact on the other. A factor that is of major importance in this research project is the environmental impact. The usage of fossil fuels has a negative impact on the environment, whereas the usage of sustainable aviation fuels has a positive impact in relation to the emissions caused by fossil fuels. From the point of view of the environment, its degradation has a negative indirect influence on (i.e. serves as an incentive to reduce) fossil fuel use, and a positive indirect influence on the usage of sustainable aviation fuels. Other elements which are related to both types of fuel are availability and price. The left side of the map was more thoroughly investigated in the present project than the right side (this could however be an interesting research topic in the future). First of all, the incentive element of the map has to be defined. In this project incentives ranging from policy makers and NGOs to research and investment were considered. The latter two fall under the innovations element, whereas the former two constitute the feasibility element (Fig. 1). Both elements have an impact on the availability of sustainable aviation fuels and on their price. Increasing incentives stimulate the innovations, which in turn positively affect the availability of sustainable aviation fuels, and in turn could potentially lower the price. Policy making and lobbying by NGO groups however stimulate the feasibility and availability, while lowering the price for these sustainable aviation fuels as well. It has to be said that this is a rather simplistic view of

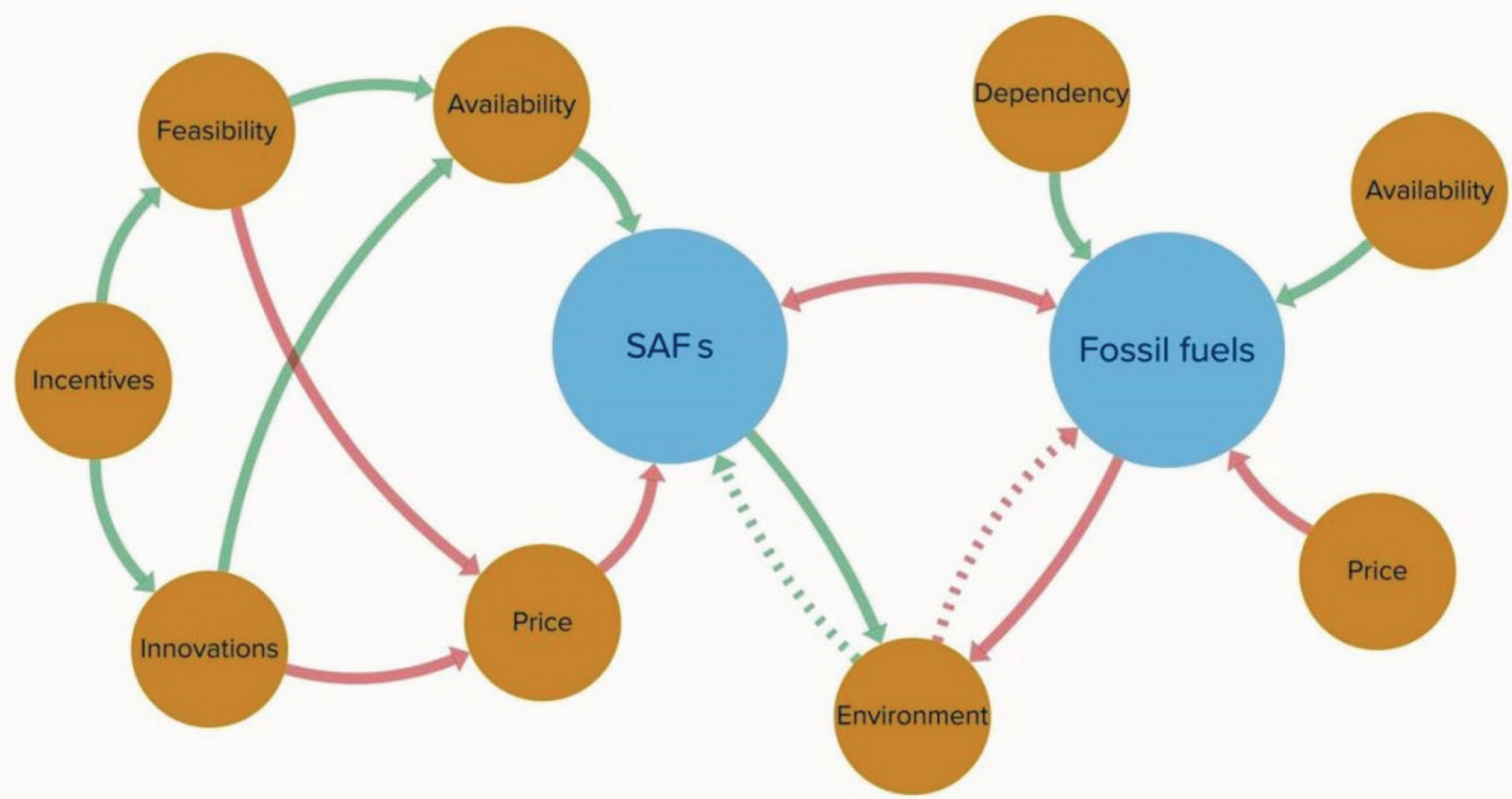

Figure 1. Systems map of the aviation industry. The elements in this systems map are restricted to the ones that are discussed here and were considered in the course of the project. SAF: Sustainable Aviation Fuel. See text for a discussion. 
such a complex system as the aviation industry and many elements were omitted due to a lack of time to generate a more thorough analysis of the industry.

From this restricted systems map it was nevertheless possible to distinguish three stakeholders that we wished to include in our research. The first obvious stakeholder is the European Commission, which falls under the element of incentives and has the power to push policies through to make sustainable aviation fuel usage a norm and stimulate producers as well as consumers of bio jet fuels. Linked to the producer side of the sustainable aviation fuels, the company Proviron was identified as a potential supplier of bio jet fuels from microalgae. Lastly, to close the triangle of producer, policy maker and consumer, Brussels Airport was identified as the consumer end of sustainable aviation fuel.

\section{Discussion}

From the above it seems like the implementation of biofuels could potentially solve the problem of $\mathrm{CO}_{2}$ emissions caused by air travel. In 2016, 1,500 passenger flights (note that there are worldwide daily about 100,000 flights) were completed with the use of a bio jet fuels blend, and this showed that switching to bio jet fuels could potentially reduce the $\mathrm{CO}_{2}$ emissions from aviation by $80 \%$ (21). Several examples exist of airlines implementing the use of bio jet fuel blends in their aviation fuels inside and outside of the EU (5). Unfortunately, these examples are only a minority of all flights taking place every day. Is the potential of sustainable aviation fuels really as promising as it looks, or are other factors still to be taken into consideration? What are the prospects of EU regulation and policy concerning these sustainable aviation fuels in the future? Are there other ways the aviation industry could become more sustainable and does the traveler himself not carry part of the responsibility?

When looking at the policy concerning sustainable aviation fuels in the EU, matters do not seem to be going very well. The airline companies strongly oppose any change to the current system and go to great lengths to minimize the impact of any policy that could potentially affect their operating costs. They even went as far as to involve foreign governments to pressurize the EC to temporarily exclude all long-distance flights going to or coming from outside of the EU from the European Flightpath Directive. This greatly reduced the impact of the Directive, thus also minimizing the environmental gain. Competition amongst airlines is currently so strong that even a few euros can make the consumer buy his/her tickets from another airline. The lobbying one might expect from many airline companies in combination with discord within the EC forces one to believe that a positive breakthrough concerning sustainable aviation fuels in the near future will not be coming from policy makers or from the airlines themselves.

The question must also be asked whether sustainable aviation fuels could completely replace the demand for fossil jet fuel. First of all, it has to be understood that the current demand for fossil fuels by the aviation industry is very large. In this case, bio jet fuels cannot simply be a solution to the high demand for fuels in aviation, as many other problems will arise regarding land use for cultivation of the crops that produce the sustainable aviation fuels. This is particularly problematic when cultivation of biofuels crops results in loss of tropical rainforest area, as is the case with palm oil cultivation in Indonesia. On the other hand, it must be said that the reduction in $\mathrm{CO}_{2}$ emissions is limited by the low ratio of energy returned on energy invested for biofuels. Relatively large quantities of fossil carbon are needed to produce the biofuels, either in the form of energy inputs during sowing, harvesting, and processing of the crops, or in the form of energy needed to produce fertilizer or pesticides needed for cultivation. It is also worth mentioning that a complete change-over to bio jet fuel could potentially give airline companies an excuse to fly even more but still claim to be 'green', something that has already happened before (rebound effect). This does not, however, fit within a true definition of sustainability and could potentially mislead travelers into believing that flying with low emissions is truly possible.

Finally, like with many sustainable problems, the broad public appears to be looking at policy makers, the industry, or even scientific research to make a change. However, as was explained, it does not seem very likely that these will be able to effectively reduce emissions in the near future and lead us back into the safe operating space of $\mathrm{CO}_{2}$ emissions. So maybe an attitude change by travelers would not require a huge effort by the individual, yet could bring about a big change and appears to be a more ethical approach to the general problematic. At the end of the day, we are still flying multiple times a year, and mostly within 
Europe. Many alternatives for medium- to long-distance traveling within the European Union exist, ranging from buses to trains. Current issues with these are accessibility, time, and price, and addressing these will require a new way of looking at traveling in general. So, finally, the problem translates into a change in culture as a whole, which in itself becomes an even more complex problematic. A system where polluting activities will cost more thanks to an integrated environmental cost could be an option, but one may wonder how many people are willing to pay more for their travel in order to preserve the environment? It should also not be forgotten that emissions caused by air travel for further than $1,500 \mathrm{~km}$ account for $80 \%$ of the total $\mathrm{CO}_{2}$ emissions from aviation. This means that the impact of finding an alternative for short-distance flights would, on a global scale, be able to address only the remaining $20 \%$ of $\mathrm{CO}_{2}$ emissions from aviation.

There are many things concerning the topic of sustainable aviation fuels that still need further research. The perspective of the airline companies would be a valuable asset to try and clarify the discord between them and the EC, although this might prove hard to achieve. It would also be interesting to put the current system of sustainable aviation fuels to the test to see if it can fit within a true definition of sustainability. Maybe an analysis of what is needed to stimulate the use of alternative modes of transportation would be interesting, and this potentially even combined with a study of public opinion or awareness of the problem.

\section{Conclusion}

Coming back to the initial question, i.e. whether biofuels are the solution for sustainable aviation, the answer from the analysis presented here is simply 'no'. The regulation of such sustainable aviation fuels could have an initial positive impact but is pushing the problem to another sector, which in turn becomes the new aviation fuel market with its own $\mathrm{CO}_{2}$ emissions. Indeed, as was mentioned above, relatively large quantities of fossil carbon are needed to produce the biofuels, either in the form of energy inputs during sowing, harvesting, and processing of the crops, or in the form of energy needed to produce fertilizer or pesticides needed for cultivation. A more viable solution to the problem can be put in the hands of the traveler by not flying over short distances. This however does not solve the larger problem at all but could eventually buy more time for more promising potential solutions to arise.

Finally, this report should not be considered as reporting on research that is fully completed, but rather as the first part of a larger research project that could be furthered by other teams as the complexity of the entire aviation-related industry is easily overlooked. There are many focuses that can be made on different parts of the systems map in Fig. 1 which would further highlight the need for transdisciplinarity. The issue of mobility in the EU and the need for certain alternatives could even prove to be a project that could generate concrete results for the student population in our continent, for example promoting train or bus travel or even pushing for more support from the EU towards European mobility by these means of transport.

\section{Acknowledgments}

We would like to extend our gratitude to Mr. D. Meadows, advisor to the director of European and international carbon markets of the European Commission.

\section{References}

(Note that for some references we had to rely on companybased reports, which cannot necessarily be considered to be independent and objective sources).

1. Boeing. (2014). Current Market Outlook 2014-2033. Retrieved from Boeing: http://www.boeing.com/assetss/pdf/commercial/cmo/pdf/Boeing_Current_ Market_Outlook_2014.pdf.

2. Airbus. (2014, November 10). Retrieved from http:// www.airbus.com/company/market/forecast

3. ICAO. (2018, January 17). Continued passenger traffic growth and robust air cargo demand in 2017. Retrieved from ICAO: https://www.icao.int/Newsroom/ Pages/Continued-passenger-traffic-growth-androbustair-cargo-demand-in-2017.aspx

4. IATA. (2017, October 24). 2036 Forecast Reveal Air Passengers Will Nearly Double to 7.8 Billion. Retrieved from IATA: http://www.iata.org/pressroom/pr/ Pages/2017-10-24-01.aspx

5. Kousoulidou, M., \& Lonza, L. (2016). Biofuels in aviation: Fuel demand and $\mathrm{CO}_{2}$ emissions evolution. Transportation Research Part D 46, 166-181.

6. International Energy Agency. (2018) $\mathrm{CO}_{2}$ Emission from Fuel Combustion. 
7. Peeters, P., Higham, J., Kutzner, D., Cohen, S., \& Gössling, S. (2016, February 27). Are technology myths stalling aviation climate policy? Transportation Research Part D, 30-42.

8. European Commission. (2013, September 11). 2 million tons per year: a performing biofuels supply chain for EU aviation.

9. IATA. (2009, June 8). Bold Industry Commitment on Environment. Retrieved from IATA: http://www.iata. org/pressroom/pr/Pages/2009-06-08-03.aspx

10. De Cleene, D. (2016, July 23). Duurzaam vliegen is een illusie. EOS.

11. Myers, J., \& Hutt, R. (2016, July 12). This visualization shows you 24 hours of global air traffic - in just 4 seconds. Retrieved from World Economic Forum: https://www.weforum.org/agenda/2016/07/ thisvisualization-shows-you-24-hours-of-global-airtraffic-in-just-4-seconds/

12. Qantas Airways. (2013). Feasibility study of Australian feedstock and production capacity to produce sustainable aviation fuel.

13. Brussels Airport. (2017). Environmental Report 2017. Brussels.
14. SkyNRG. (2018). About SkyNRG. Retrieved from SkyNRG: http://skynrg.com/about-skynrg/

15. ATAG. (2011). Powering the future of flight: The six easy steps to growing a viable aviation biofuels industry.

16. EU. (2011). EU Declaration Biofuels in Aviation. Brussels: EU.

17. Pye, D. \&. (2016). Biofuels for Aviation: Review and analysis of options for market development. Insight Energy.

18. Boeing. (2013). Boeing Annual Report. Retrieved from Boeing: http://www.boeing.com/assets/pdf/companyoffices/financial/finreports/annual/2014/annual_ report.pdf

19. Airbus. (2012). Global Market Forecast 2012-2013.

20. IATA. (2016, October 18). IATA Forecasts Passenger Demand to Double Over 20 Years. Retrieved from IATA: http://www.iata.org/pressroom/pr/Pages/201610-18-02.aspx

21. ATAG. (2014). ATAG Aviation Benefits 2014. Retrieved from Aviation Benefits: https://aviationbenefits. org/media/26786/ATAG__AviationBenefits2014_ FULL_LowRes.pdf 


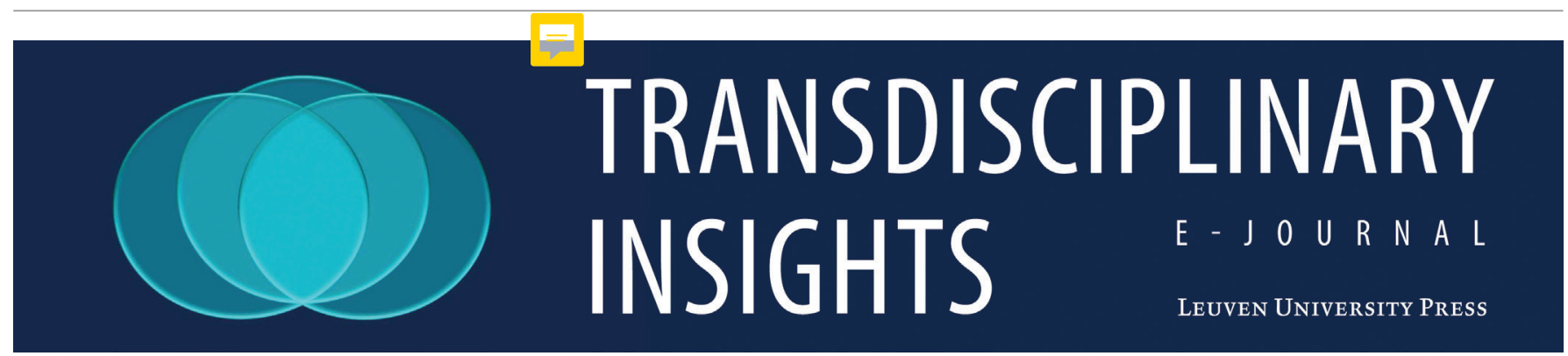

\section{Student Team Sustainability Research Projects as an Approach to Education for Sustainability at the University Level}

\section{A case for thorium power plants in Belgium? Analysis of the viewpoint of two political parties}

\author{
T. Peirs, ${ }^{1, *}$ E. Philips, ${ }^{1, *}$ V. Verswijvel, ${ }^{2, *}$ \\ P.-J. Vroom, ${ }^{1, *}$ N. Severijns, ${ }^{3}$ and \\ G. Ceulemans ${ }^{4}$ \\ ${ }^{1} \mathrm{KU}$ Leuven, Master's student Geography, Leuven, \\ Belgium;
}

${ }^{2} \mathrm{KU}$ Leuven, Master's student Geology, Leuven, Belgium;

${ }^{3} \mathrm{KU}$ Leuven, Department of Physics and Astronomy, Leuven, Belgium;

${ }^{4} \mathrm{KU}$ Leuven, Department of Chemistry \& Specific Teacher Education Centre of the Natural Sciences (option Chemistry), Leuven, Belgium.

* These authors contributed equally to this work.

\section{Summary}

The long-term Belgian energy policy considers a nuclear phase-out. In view of shifting towards a sustainable national energy policy, it would be useful to not rule out nuclear technologies in advance, but instead incorporate the assessment of possible alternatives to the classic uranium-based nuclear power. More precisely, thorium has positive benefits for future energy applications. This paper identifies the major key actors in this debate and the different interactions between individual nodes of the framework. Focus is put on the political and social aspects of the topic. Results show that even key actors do not necessarily reach consensus on the sustainability framework. This, together with the polarization of society as regards nuclear power, emphasizes the complexity of the debate, which can be tackled only through transdisciplinary, independent research and an open debate.

\section{Introduction}

In 2016, Belgium produced a total of $79.82 \mathrm{Twh}$ of electricity. Nuclear energy makes up about $52 \%$ of this, while $29 \%$ is produced by fossil fuels, about $7 \%$ by biomass, and only $12 \%$ comes from renewable sources, such as solar, wind, and hydro energy. Belgium has a total net import of 6.18 TWh (12). The different governments in Belgium recently accepted a policy that resolutely opts for sustainable energy and a nuclear phase-out in 2025 (1). To compensate for the loss of electricity from nuclear production and prevent a blackout, in April 2019 the Belgian government passed a law allowing the support of companies that consider investments to construct a number of new gas-powered power stations (2). Yet, regarding the EU Climate Action 2020 , every member state should reduce its greenhouse gas emissions by $20 \%$ compared to those of 1990 , make $20 \%$ of energy production renewable, and make a $20 \%$ increase in energy efficiency (3). According to a report of the European Commission, Belgium will miss the mark for renewable energy by $3.5 \%$ (4). The planned gas-powered plants are questionable if one is 
thinking in terms of sustainable energy. It is therefore interesting to consider other possibilities for the production of electricity which may not be renewable, but at least will not directly contribute to carbon dioxide emissions, such as e.g. thorium-based nuclear power plants. In addition thorium-based nuclear power has several advantages compared to uranium-based nuclear power, such as e.g. the greater abundance and safety (see the Appendix). Nevertheless, there are disadvantages or shortcomings as well, related to technology, politics, economics, and social acceptance of nuclear power plants. These shortcomings are important to evaluate, especially in terms of sustainability. The aim of this report is to discuss the energy policy and the role of society in a setting of sustainability to ask whether politicians' arguments are in line with sustainable politics and to investigate if we can propose a sustainable electricity plan for the future.

The research reported here was carried out within a sustainability framework. Sustainability frameworks differ from person to person and between organizations and parties. Nevertheless, to discuss sustainability a framework is needed. The framework used here does not pretend to be the one and only possible framework for sustainability, but it is necessary to define the limits of the report and the framework used here. The first important element is planetary boundaries, which define the limits within which humanity can live (5). When those limits are surpassed, instability of the earth's systems may occur. One pillar of sustainability is the ecological or environmental one, the other two important pillars being the social and economic ones. The social pillar takes fairness and equity into account. An acceptable solution cannot benefit some people while strongly harming the interests, livelihoods, and quality of life of others. It should even reduce the gap between rich and poor. The economic pillar is also incorporated. The economy cannot be harmed to benefit the other parts of sustainability. This does not mean, however, that economic growth is an absolute necessity. Overall sustainability means that the needs of the current generations can be fulfilled without harming the possibilities and opportunities of future generations (5).

The research team consisted of three geographers and a geologist, meaning that the inter/transdisciplinarity in the team was limited. It was attempted to improve this by interviewing several persons in different political parties. Note, however, that since only two parties responded to our request, one party being a member of the present political majority and the other being an opposition party, one can wonder whether the discussions with these two parties are representative of the contemporary political discussion. It can further also be questioned whether the contemporary political discussion really is the reflection of public opinion on the topic, and whether the members of the political parties that were interviewed can be considered real experts on the matter. Apart from political parties, a few professors from the faculty of social sciences were also contacted and provided us with some relevant scientific publications (e.g. 6).

Different sources of information were used to gather the necessary data. The largest amount of information came from different articles, books, and other literature. Yet the most important source of information came from the interviews with the political parties. This offered a unique insight into the decision-making process in the country.

\section{Analysis}

\section{System and stakeholder map}

Determining the future electricity mix is a complex sustainability problem, e.g. when considering whether thorium nuclear power could have a place in this mix. This complexity mainly originates in the vast number of partners or stakeholders that are involved and the processes that are impacted. One would think this would result in a complex and diverse approach to the subject. Yet, as this would result in complicated and possibly ambiguous results, a lot of effort was put into trying to simplify and delineate the subject as well as possible. Systems thinking was used for this.

Systems thinking is extremely relevant to apply in complex sustainability problems. It is the skill to examine the (inter) connections and relationships between objects/stakeholders and events, and the objects and events themselves. Having done so, it is possible to predict how changes in one component of the system will lead to changes in another (7). To visualize the system a concept map was created (Fig. 1).

Great effort was put into the mapping of the different stakeholders involved in the problem, thereby using the so-called salience model of stakeholders (19). These stakeholders are shown in the system map, which also shows the connections between them. 


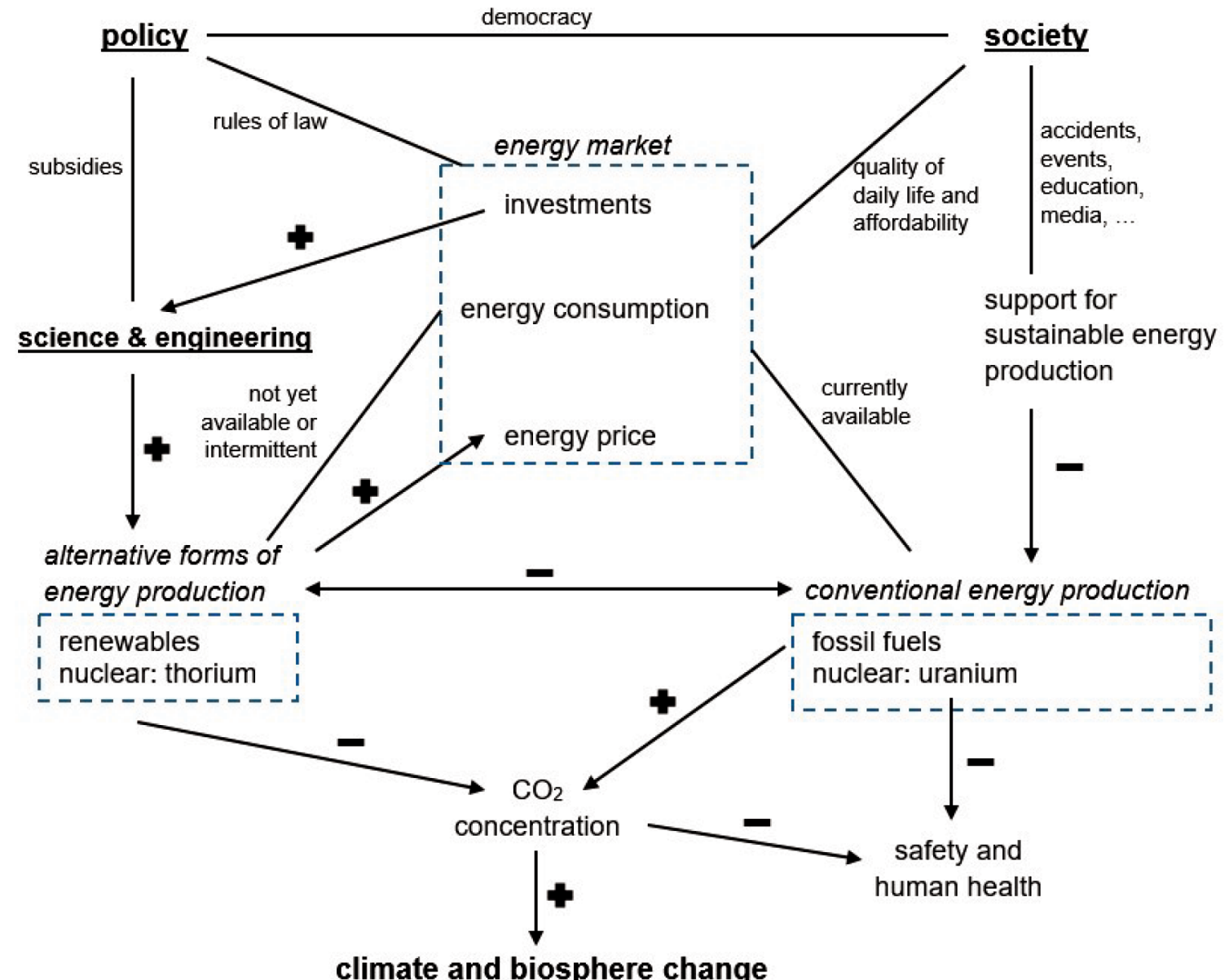

climate and biosphere change

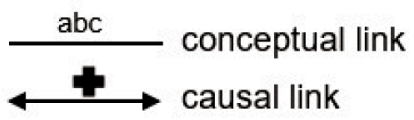

Figure 1. Integrated system and stakeholder map for addressing the potential role of thorium-based nuclear power plants in a sustainable electricity mix, with identification of the stakeholders and the connections between them. A distinction was made between conceptual links and causal links. The conceptual links are based on non-causal relations and can be described using categories, objects, goals, principles, ... The causal links are increasing or decreasing causal relations, i.e. if one or both elements changes, this will affect the other element as well. Dotted-lined boxes list components of the element listed on top of the box (e.g. investments, energy consumption, and energy price are different components of the energy market that we distinguish here). (More details are given in the text).

Society definitively is an important stakeholder because of the power and legitimacy manifest in democratic elections. This stakeholder consumes energy and therefore an adequate energy supply is needed. If society does not want the energy to be produced by conventional techniques, there will be great urgency to find alternative techniques. The legislature is an important stakeholder as well. Politicians are elected to represent the population. They have the power and legitimacy to govern. The urgency can depend on ideology or the political party to which one belongs, or even on what society wants. Subsequently, the scientific community is a stakeholder with no power, but usually with a lot of urgency and legitimacy, i.e. when considering climate change and the United Nations Climate Change Conferences.

The integrated system and stakeholders map shows interrelations between different elements of the system and the stakeholders, while indicating also the aspects linking them. Where relevant it illustrates whether a 
relation that is shown has an enforcing (plus sign) or rather a reducing (minus sign) influence (causal links/ relations). Thus, e.g. (see figure 1) support for sustainable energy production leads to a reduction in conventional energy production, while conventional energy production has a negative effect on safety and human health, and it and alternative forms of energy production are mutually exclusive, alternative forms of energy production lead to higher energy prices, and science and engineering have a positive effect on alternative forms of energy production.

Due to the complexity of the system, a leverage point was necessary in order to get a good insight into the system. It was therefore decided to focus in this report on the political aspects, without ignoring other parts, but an entry point is needed to say something about the complex system. Thus, the system map (figure 1) does not have the ambition to be complete, but rather focuses on those aspects that have a relation with and can be influenced by politics and policy making, as this is the focus of this project.

Considering longer timescales, i.e. several decades, thorium could be a sustainable part of the Belgian electricity mix, since it could meet all three subparts of sustainability. Ecologically, the $\mathrm{CO}_{2}$ emissions are significantly lower compared to those of fossil fuels. Compared to uranium-based nuclear energy, several orders of magnitude less nuclear waste is produced. The fuel is further harder to use for manufacturing nuclear bombs and is much safer in terms of reactor stability. For more details the reader is referred to the appendix.

\section{Opinions of political parties}

In Belgium there are a rather large number of political parties. There are three traditional parties, i.e. Christian democrats ( $C d \& V$, center to leftish), socialists (SpA, left-wing), and liberals (Open Vld, center to right-wing), as well as the ecologist party (Groen, left-wing). These four parties each have a (fully independent) sister party in the other (Flemish, respectively Walloon (Frenchspeaking) part of the country). On the Flemish side there are in addition two right-wing parties, a democratic one (NVA) and an extremist one (Vlaams Belang). On the Walloon side there is a rather extreme left-wing party. Originally only the ecologist parties were opposed to nuclear energy. They were soon followed by the socialist parties. Other parties were in general in favor. In 2003 the government (then including the socialist, the ecologist, and the liberal parties) decided that Belgium was to phase out all nuclear power plants by 2025 . Following the nuclear accident in Fukushima (Japan) in 2011 the Belgian population became strongly polarized about the issue of nuclear energy. The Christian democrat and the liberal parties then joined the parties that were already opposing nuclear energy, although it would not be surprising if they were to change their opinion again if the electricity supply were at stake when shutting down all nuclear power plants. The more extreme right-wing parties (NVA and Vlaams Belang) are openly in favor of nuclear energy.

Representing the policy making stakeholders in our project were the liberal party ('Open VLD') and the green party ('Groen'). A politician from the Christian democratic party was also contacted for an interview, but unfortunately no positive answer was received. In general, Open VId supports the renouncing of nuclear energy. It substantiates this view with a few very clear arguments. "The classical argument: nuclear energy in its current state produces waste" (8). Another argument against nuclear energy, according to Open Vld, is that "nuclear energy is not compatible with intermittent energy sources". However, Open Vld keeps an open mind towards innovative new technologies for producing electricity and does not rule out the option of thorium-based nuclear energy. Open VId knows the advantages of thorium and can even provide some interesting arguments: "Thorium is a raw material that is 'geostrategically' far less delicate compared to uranium" (8).

Compared to renewables such as wind and solar energy, thorium-based electricity is less clean, but it could be used together with them in an energy mix, serving as baseload for example. Groen counters this (9) by referring to a study carried out by Energyville (10). This states that in a scenario where Belgium renounces nuclear energy and puts more effort into renewable energy and energy efficiency the country will produce less $\mathrm{CO}_{2}$ compared to a situation where two nuclear power plants are kept in operation (10). It is to be noted though that this particular scenario assumes the import of about $30 \%$ of electricity from neighboring countries, thereby attributing the related possible $\mathrm{CO}_{2}$ emissions to those countries ...

In order to make thorium-based electricity an economically feasible option more research is needed. Thorium is at the moment too expensive to consider, if even 
technically possible, certainly for a country as small as Belgium. This is the biggest issue for Open Vld in considering the possibility of implementing thoriumbased electricity in Belgium. Research in countries like India and China could also benefit the global energy market, but at the moment too little is communicated to consider its economic feasibility.

The social component of thorium power is mainly limited by the social acceptance of a nuclear power source. Contemporary public opinion in Belgium is against nuclear power. Clear communication about the difference between thorium- and uranium-based nuclear power will be needed in order to change public opinion if thorium-based electricity were to be considered. Even a political party like Groen seems to have a hard time distinguishing between the two. They use similar arguments against thorium to those they use against uranium. They say that the supply of thorium is indeed greater compared to uranium, but still remains limited. They further argue that thorium-based nuclear energy indeed produces less waste, but that "even in small amounts, this waste can be dangerous". They even use fear due to uranium-based nuclear disasters also for the case of thorium: "Nuclear disasters and the risks connected to nuclear energy can hardly be associated with emotionality." (11). How small the risk is does not matter to them as "the risk will always exist". Of course, a $100 \%$ no-risk scenario is impossible for any technology. Open VId wants to change public opinion by using a 'cool-down' period, thus allowing the negative connotation to fade from public memory and then building public opinion from scratch. Considering the timescale needed to meet the other two sustainability criteria, they consider there is enough time for this to change. The two political parties further state they are open for a discussion about this. Groen also stresses they are open for a debate on alternative nuclear energy if it is performed with transparency and if all important factors are included. Those factors are: price, uncertainties, risks, time perspective, already deployed means, insurance/liability, problems on power, and complementarity with renewable energy sources. The importance of fundamental research is also recognized, but the implementation greatly differs. Although Open Vld recognizes the possible advantages of thorium, it aims for investments in research and development for the broad realm of possible new electricity production technologies. It would be a pity, it considers, if Belgium were to focus mainly on a single technology which could, in the end, prove to be not very effective. The mere fact that China and India are heavily investing in research on thorium is due to their energy race and their steeply increasing need for electricity in the coming decades. According to Open Vld, an open mind should be kept towards the possibility of buying thorium technology and applying it here. This will, however, also be bought with tax money. "The nuclear sector should accept that a total nuclear rejection is necessary at this moment, and they should invest their means in intensive research." (8). Groen argues that all the means that have been put into research on nuclear energy should instead be put into energy efficiency, renewable energy, and the development of a flexible, low carbon, and democratic energy system. If nuclear power plants are to be renounced, Belgium should invest in extra conventional energy sources like natural gas. Groen states: "The least amount of $\mathrm{CO}_{2}$ emission will be produced when we decrease our energy consumption and get all our electricity from solar and wind energy." They also claim following statement: "Sustainability is not only a matter of reducing $\mathrm{CO}_{2}$ emissions. Storing long-lived nuclear waste and mining uranium is not sustainable at all."

\section{Discussion}

It is clear that there is a variety of possibilities for thorium-based power, but there are also a lot of problems and obstacles that limit the possibilities in the short term. At the moment the most important limitation is technical feasibility. One should keep in mind that, when starting to take measures to make thorium energy socially acceptable or start planning the implementation of thorium-based power into the electricity network, the technology might be commercially available only in about 15 years from now. As this timescale is longer than the horizon over which most political decisions are usually made, thorium energy was not considered in the inter-federal 'Energiepact' (2050). One can wonder whether this long period is reasonable, also in view of the fast technological developments in the electricity production sector. Clearly, fundamental research, political will, and communication with the public would be necessary in order to make thorium a part of a sustainable electricity mix.

Overall, the politicians assess all three aspects of sustainability to be equally important but some nuances can be found in their reasoning. Groen claims that 
realizing the three aspects together is essential. The economic goals should be realized within the borders of our planet and in a socially responsible way. A distribution of burdens and profits should be made, thereby keeping social justice in mind. Open VId thinks more within an economic framework. From its point of view, internalization of external costs is the best way to link the ecological and social aspect to the economic one. According to Open VId, prosperity should be measured not only by GDP, but also by sustainability and even SDGs.

When talking about nuclear energy, Groen always refers to the currently existing nuclear power plants. When the alternative, thorium-based nuclear energy is mentioned they say that they know about the new technology. However, Groen dismisses this option very readily by claiming that the progress in this new technology is not yet advanced enough. Also, when mentioning that thorium shows some clear advantages over uranium, Groen still sees those two as almost equally dangerous and wants to have a no-risk policy. In our opinion, that is impossible. Groen refers to a document from Energyville claiming that dismantling all nuclear power plants and partly replacing them with natural gas plants will lead to a decrease in $\mathrm{CO}_{2}$ emissions. What it fails to mention is that in this given circumstance Belgium will have to increase its electricity imports from $14.4 \%$ to $28.4 \%$. The question is whether the $\mathrm{CO}_{2}$ emissions of those countries are taken into account. Another point worth mentioning is that those calculations were based on the best economic solution, so the question arises whether the ecological counterpart of sustainability is viable. This is a direct contrast with the views of the party.

Open VLD seems to have less problem with the idea of thorium nuclear power. Its idea of sustainable energy is based on economics. When all costs are internalized, it considers the three pillars of sustainability will become one and the question of sustainability will be resolved on its own. Attached to this is also the idea of circular economy, an idea that is less relevant in this context but is a concept that was strongly emphasized.

The most striking thing about the interview of Open VLD was the solution for the social acceptance of thorium energy. A cool-down phase was proposed. This could probably be an effective way but might be ethically questionable. It could also cause important knowledge concerning nuclear practices to be lost.
Overall, Open VLD made a more informed and nuanced impression. It has to be mentioned that this can be strongly influenced by the way our questions were answered. Due to the face to face contact, Open VLD had the opportunity to add to and comment on statements and directly react to considerations and remarks. It was Groen's own choice to answer the questions in writing, although it is a topic that plays a major role in their program. But at least they answered, in contrast to other parties that also have a strong opinion on the topic of energy and nuclear power but did not cooperate in this research.

\section{Conclusion}

Currently, the Belgian energy policy consists of closing all nuclear reactors, while reevaluating annually whether this course is to be maintained. This policy considers a shorter time period compared to that for which thorium reactors can be considered feasible. This way, thorium-based nuclear power plants can be considered as one of the many possible long-term solutions to the energy problem that still need a lot of research and development to be efficiently employable in a sufficiently large scale, like nuclear fusion, renewables, or hydrogen. It could be part of a long-term solution, fitting into a broader sustainable energy system, but for short time scales it has limited potential.

The long time span and the complexity of the system make it very hard for this both in time and in possibil tie: rather limited, research project to make strong recommendations considering the need for implementation of thorium power in the Belgian energy system. This project focused deliberately only on the policy aspects while (indirectly) the risk perception of society was taken into account as well. Clearly, there are a lot more stakeholders than those that could be considered in the scope of this research. All of them need to be considered in order to have a chance to arrive at a sustainable solution.

Considering sustainability, an important obstacle was encountered, most likely a problem for any sustainability issue. It concerns the framework of sustainability. All stakeholders have a different view on sustainability, even if they say otherwise. The first thing that needs to be done is to reach a consensus on what sustainability is, also considering unspoken association and seemingly self-evident issues. Only then can a real discussion about sustainability be started. This first step is already a 
very difficult one. Inter- and probably even transdisciplinarity in the teams handling the sustainability topic could help in offering an open view of the framework. In addition, using other possible scenarios, such as e.g. foresight scenarios (18), might be of interest as well.

\section{Acknowledgments}

The authors want to thank Johan Danen, WillemFrederik Schiltz, Kristof Calvo and Bart Vyncke for their collaboration in this research.

\section{Appendix - Technical information on thorium- based nuclear power}

Thorium is rather abundant, making the available amount sustainable on a human timescale (13). It is also found in association with other rare earth minerals, meaning that it will be mined anyway. The local effect of the extra mining of Thorium will be limited as existing infrastructure can be used (14). Furthermore, thorium is - unlike uranium- insoluble, limiting the danger of polluting water bodies and river courses in the proximity of mines (15). It has to be noted that the figures for thorium resources are estimations based on association with other rare earth minerals, as thorium is not a primary exploration target (15). The biggest challenge in exploiting thorium on a large scale is its purification. Thorium is separated from the other associated minerals with the use of acid and alkaline solutions. This process is not yet optimized, as thorium is not exploited on a large scale, leaving room for improvement (15).

Five major advantages of thorium-based nuclear reactors are:

- Thorium has been mined already, but is hardly used;

- The waste of thorium nuclear energy has far less potential for nuclear proliferation.;

- Less waste is produced which, moreover, has a radioactive half-life sufficiently small that it has to be stored for only about 300 years;

- Thorium-based power plants provide the ability to process the long-lived waste of uranium-based nuclear power plants;

- Higher safety (15)

Thorium-232 is fertile and has to absorb a neutron to become Thorium-233, which decays to Uranium-233. Uranium-233 can be used as reactor fuel. The fission process needs a fissile element to supply the neutrons required to keep the process going $(14,15)$. However, "breeding" is possible, limiting the need for input materials to a regular input of Thorium-232 (14-16). So far, several reactor types have been able to use thorium as a fuel, among which is a Liquid Fluoride Thorium Reactor (LFTR), which avoids structural damage to the fuel rods and in principle enables the total burn-up of the fuel.

Thorium reactors, especially LFTR, are somewhat more efficient than traditional uranium plants (16). Furthermore, they produce fewer, less long-living nuclear waste that is less suitable for producing a nuclear bomb $(14,17)$. The liquid promotes the inherent stability of the reactor, by solidifying when cooled down (17).

Nevertheless, a facility for preparing the fuel and for reprocessing used fuel is needed. Provided the required very high safety standards that are typically applied in nuclear industry are followed, this should not constitute any major burden for society. Note that this fuel processing facility can also be used to separate fission isotopes of interest for medical usage, such as e.g. ${ }^{99} \mathrm{Mo} /{ }^{19} \mathrm{Tc}$ that is used in Computer Tomography scanners.

\section{References}

1. "Het Belgische energiebeleid." n.d. Nucleair Forum. Accessed March 4, 2018; https://www.nucleairforum. be/thema/energie/het-belgische-energiebeleid.

2. Belgische Kamer van Volksvertegenwoordigers, Voorstel van resolutie over het Belgisch Interfederaal Energiepakt, DOC 54 2883/001 (January 11, 2018). NWS, VRT. (2018). "Waarom we mogelijk 12 nieuwe gascentrales nodig hebben, en waarom die er maar niet komen." vrtnws.be. 23/02/2018. https://www.vrt. be/vrtnws/nl/2018/02/23/waarom-we-mogelijk-12nieuwegascentrales-nodig-hebben--en-die-e0/.

3. Anonymus. (2016) "EU Climate Action." Text. Climate Action - European Commission. November 23, 2016. https://ec.europa.eu/clima/citizens/eu_en.

4. NWS, VRT.(2017). "Europa'haaltklimaatdoelstellingen tegen 2020', maar België moet nog een tandje bij steken." vrtnws.be. 08/11/2017. https://www.vrt.be/ vrtnws/nl/2017/11/08/belgie-haalt-klimaatdoelstellin gen-2020-niet/.

5. Rockström, Johan, Will Steffen, Kevin Noone, Åsa Persson, F. Stuart Chapin, Eric F. Lambin, Timothy M. Lenton, e.a. 2009. "A Safe Operating Space for Humanity”. Nature 461 (7263): 472-75. https://doi. org/10.1038/461472a.

6. Vyncke B., Perko T., Van Gorp B. (2017) Information Sources as Explanatory Variables for the Belgian 
Health-Related Risk Perception of the Fukushima Nuclear Accident. Risk Analysis, Vol. 37, p. 570

7. Blewitt, J. (2008) Understanding sustainable development. London: Earthscan, pp. 55-58.

8. Open VId (2018). Interview with a representative of the liberal party Open VId (April 2018).

9. https://www.groen.be/dossier_kernenergie.

10. Energyville (2017). http://www.energyville.be/nieuwsbericht/energyville-introduceert-objectievevooruit blik-op-de-belgische.

11. Groen (2018). Interview with a representative of the green party Groen (March 2018).

12. "Statistieken Elektriciteit | FEBEG Federatie van de Belgische Elektriciteits- En Gasbedrijven." n.d. Accessed February 26, 2018. https://www.febeg.be/ statistiekenelektriciteit.

13. Revol J.-P., 2015. "Thorium: An Energy Source for the World of Tomorrow." In EPJ Web of Conferences, 98:05002. EDP Sciences.
14. World Nuclear Association. 2017. "Thorium.” World Nuclear association.

15. Bryla T., Parlato V. 2017 "Thorium reactors: the search for more sustainable future." Conference paper Pittsburgh Swanson School of Engineering

16. Seneda J.A., Lainetti P.E.O. 2010. "Use of thorium in the generation IV molten salt reactors and perspectives for Brazil." Associçãa Brassileira de energia nuclear. American Scientist

17. Hargraves R., Moir R., 2010. "Liquid fluoride Thorium Reactors: an old idea in nuclear power get re-examined." American Scientist.

18. http://www.foresight-platform.eu/community/forlearn/ how-to-do-foresight/methods/scenario/

19. Mitchell R.K., Agle B.R. and Wood D.J. 1997. "Toward a Theory of Stakeholder Identification and Salience: Defining the Principle of Who and What Really Counts. The Academy of Management Review, Vol. 22, No. 4, p. 853. 


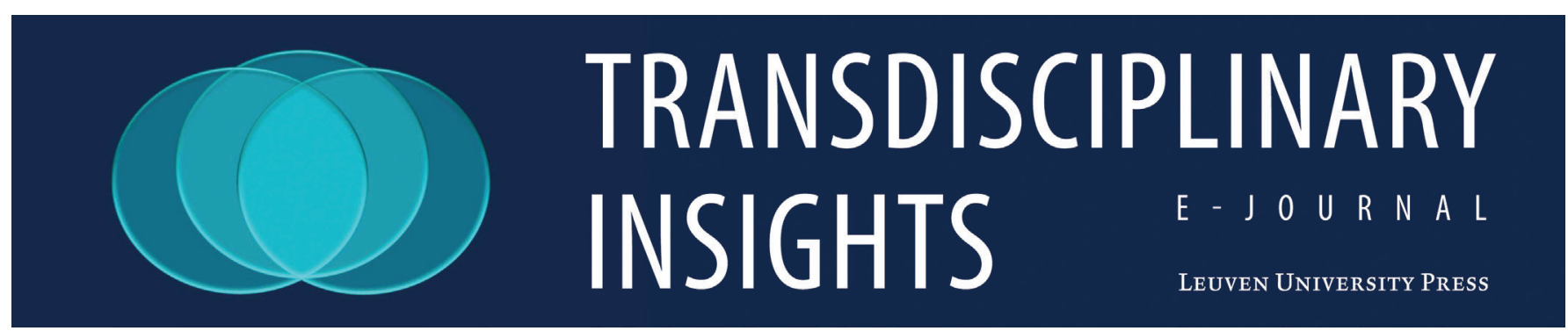

\section{Student Team Sustainability Research Projects as an Approach to Education for Sustainability at the University Level}

\section{A sustainability comparison of fishery techniques}

B. Dewulf, ${ }^{1, *}$ E. Obad Aghandum, ${ }^{2, *}$

V. Smeesters, ${ }^{3, *}$ F. Van Hooreweghe, ${ }^{4, *}$

H. Vermeulen, ${ }^{5, *}$ F. Volckaert, ${ }^{6}$ N. Severijns, ${ }^{7}$ and G. Ceulemans ${ }^{8}$

${ }^{1} \mathrm{KU}$ Leuven, Master's student Chemistry, Leuven, Belgium;

${ }^{2} \mathrm{KU}$ Leuven, Master's student Geology, Leuven, Belgium;

${ }^{3} \mathrm{KU}$ Leuven, Master's student Mathematics, Leuven, Belgium;

${ }^{4} \mathrm{KU}$ Leuven, Master's student Biology, Leuven, Belgium;

${ }^{5} \mathrm{KU}$ Leuven, Master's student Statistics, Leuven, Belgium;

${ }^{6} \mathrm{U}$ Leuven, Department of Biology, Leuven, Belgium;

${ }^{7} \mathrm{KU}$ Leuven, Department of Physics and Astronomy, Leuven, Belgium;

${ }^{8} \mathrm{KU}$ Leuven, Department of Chemistry \& Specific Teacher Education Centre of the Natural Sciences (option Chemistry), Leuven, Belgium.

*These authors contributed equally to this work.

\section{Summary}

Scientific research shows that the electric trawling technique is a more sustainable technique for the catching of plaice compared to the classical trawling technique. Even though electro trawling has its limitations with respect to sustainability, this technique is less damaging to the marine ecosystem. In January 2018, the European Parliament voted on a ban on the electric trawling technique based on the limited scientific evidence supporting the sustainability of the technique. Bloom Association also urges a ban not just on the electric trawling method but also on the classical trawling method, labeling them both as dangerous to the marine environment. For both the EU and Bloom, socioeconomic factors also play an important role in the argumentation in favor of the ban. Continued discussion among the stakeholders and subsequent compromises are suggested for reaching a lasting solution to the problem of selecting the most sustainable flatfish fishing technique.

\section{Introduction}

On January 16, 2018, the European Parliament voted on an amendment proposing an EU-wide ban on the use of electro trawling, a relatively new, efficient, and (ecologically) promising technique in flatfish and brown shrimp fishery. This decision was somewhat controversial, given the possible eco-friendliness of electro trawling (also called pulse fishing, electrofishing, or electric pulse fishing). This project focuses on the comparison of classical beam trawling and electro trawling in flatfish (specifically plaice) fishery. This 
comparison will mainly address the ecological side of the issue, but the social and economic pillars also need to be discussed concisely.

The first step in the comparison consists of identifying the stakeholders and determining their relationship to each other in a systems map. All stakeholders were subdivided according to urgency, legitimacy, and power. This information can consequently be used to perform a stakeholder analysis and flow sheet providing an overview of all inputs and outputs at each stage of the flatfish fishery and food industry. This is the life cycle inventory $(\mathrm{LCl})$ and can be used to determine the impact of both fishery techniques. We also performed a literature study, mainly providing information on the ecological side of the story. To get a better view on the socio-economic part of the comparison, several stakeholders were interviewed. The most important goal of this was to see what their values and ideas are and how they relate to each other.

Before starting the sustainability comparison between classical beam trawling and electro trawling, we would list below the important criteria for 'sustainable trawling':

- Sustainable trawling minimizes damage to the marine ecosystem and non-target species, thus avoiding the loss of resilience of the ecosystem and preserving it for future generations.

- Sustainable trawling respects quotas, which are such that the flatfish population does not decrease but instead increases back to its natural size, thereby preserving this valuable resource for future generations.

- Sustainable trawling should be possible for all fishermen, from those using small-scale and traditional fishing methods to industrial fishery. Regulations (e.g. organizing and dividing the sea areas for different sizes of fishery industries) and efficient controls could achieve this.

The student team that performed this project consisted of master's students in chemistry, biology, geology, mathematics, and statistics. During this project, the team not only learned a lot about fishing techniques and their ecological, political, and economic aspects, but also learned about how to collaborate efficiently in an interdisciplinary team. Experience was also gained on how to use the different backgrounds and expertise of the team members in such a way as to enrich discussions and gain a deeper understanding of this complex problem. In addition, it was realized that open, continuous discussion with a number of people with different backgrounds is indeed needed to gain a better understanding of situations as complex as the ones encountered in sustainability issues.

\section{Analysis}

\section{Value prioritization, systems map, and stakeholder analysis}

During this project it was decided to take the ecological and socio-economic factors as our prioritized values. Since the original motivation for the development of electro trawling was the reduction of damage to the marine ecosystem, the ecological pillar was an obvious choice. Besides, as scientists, the authors were most intrigued by the ecological aspect of the problem. Apart from the marine environment, a strong concern was also felt for the well-being of the fishermen and human beings in general. It was therefore decided to consider the socio-economic aspect as the second prioritized value. However, apart from the ecological and socioeconomic aspects, many other values are related to this problem and different stakeholders might prioritize different values. In order to get a broad overview of all related stakeholders and their prioritized values a systems map was developed, shown in Figure 1. The systems map represents a nested model, with the social, legal, and economic factors contained within the ecological framework. Notice that fishery industries exceed the ecological boundary, which represents the overexploitation of marine resources.

For the marine environment as a stakeholder, it is important to bring catch rates back to a level where a constant fish population can be maintained and the resilience of the system is preserved. The environment is primarily peopled by NGOs, and to a certain extent by the consumer through its public opinion.

The fishery and food industries focus on two main values: (i) they want to make a profit from which they can live comfortably, (ii) they do not want the fish to go extinct because of overexploitation, so they follow the quota imposed by governments. These two values provide a trade-off. On the one hand, fishermen want to catch as much as possible for socio-economic benefits in the short term. On the other hand, they do not want to overexploit the resource stocks in the long 


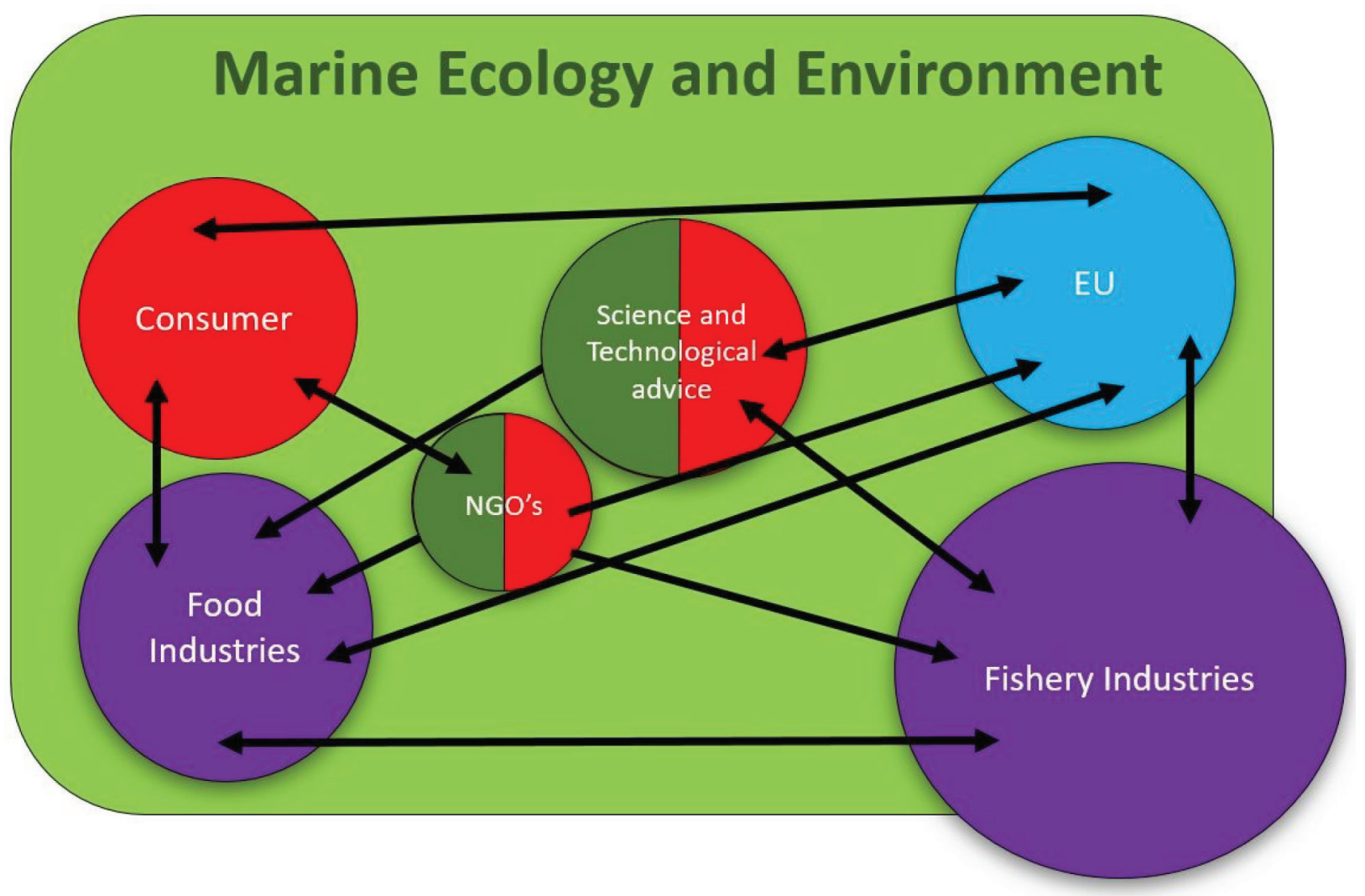

Figure 1. Systems map showing the most important stakeholders. The different interests of all stakeholders are represented by different colors: green = ecologic; red = social; purple = economic; blue = governmental.

term. As regards electro trawling their views are divided. The Dutch industrial fisheries are in favor, because of the environmental and economic benefits. Besides, a large part of the Dutch fleet has already switched to electro trawling. The traditional small-scale fisheries (mostly in Belgium) do not like electro trawling because of the high investments that have to be made in order to switch to this technique and because of the unfair competition with the industrial fisheries using electro trawling. The government (the European Union in this case) has to take the opinions of all stakeholders into account in order to make fair decisions. Consumers are of special importance to the government because it is they who give the government legitimacy through the elections. The most important values for the government as a stakeholder are (i) keeping the citizens' support and (ii) providing legislation that ensures the continuation of society as we know it. The socio-economic values are therefore often the most important factors for decision-making.

The NGOs and consumers act as the ecological, economic, and social soundboard of earth and all its residents. Their values vary: NGOs primarily support ecological preservation but are also concerned by social issues. NGOs can influence the opinion of the consumer as well as the government. The consumer primarily sees the socio-economic issues. Consumers are responsible for the demand side in economic activities and also here. In general, people do not want to reduce their fish consumption but are open to changes that can preserve the marine ecology. For example, a significant number of people are willing to pay more for fish that has been caught sustainably. Indeed, in research on this issue performed in eight European countries (i.e. Finland, France, Germany, Ireland, Italy, Poland, Spain, and UK) three clusters were found: On an average of all countries, the percentage of participants in the cluster with no 'willingness to pay' (WTP) was $47 \%$, but $44 \%$ were in the 'medium WTP' cluster, and $9 \%$ in the 'High WTP' cluster (26).

Technological support and knowledge provided by science are important aspects that should be considered by all stakeholders. Further, not only are the prioritized values different for all stakeholders, but also the means by which these values are reached. The stakeholders can therefore be distributed (using the so-called salience model of stakeholders of Mitchell 


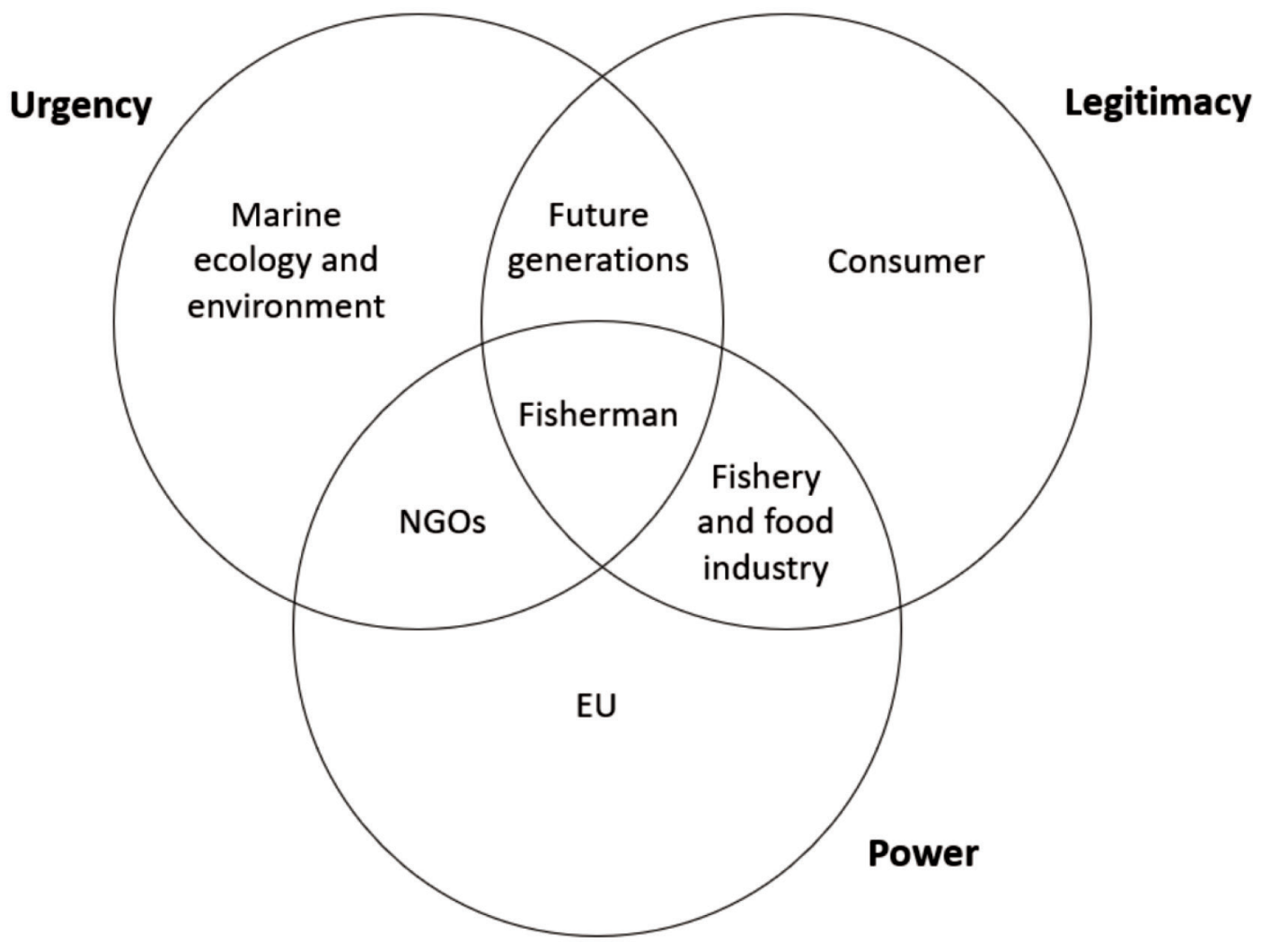

Figure 2. Distribution of the stakeholders according to urgency, legitimacy, and power.

et al. (1)) according to urgency, legitimacy, and power, as is shown in the figure below (Fig. 2). A more detailed discussion of the stakeholders in this sustainable fishery project is found in Appendix 1.

It was attempted to interview three of these stakeholders: a spokesperson from the EU, a scientific expert in electro trawling, and a representative of an NGO with a strong opinion on electro trawling. Unfortunately, we could not reach a spokesperson from the EU. The results of these interviews will be discussed in a later section.

\section{Life cycle inventory}

Although this project focuses on sustainability at the fishing stage, the processing and consumption of captured fish are equally important with regard to sustainability. We therefore developed a stakeholders' flow sheet including all different stages from sea to plate (Fig. 3). Based on this flow sheet, we constructed a life cycle inventory $(\mathrm{LCl})$ showing the main inputs and outputs at every stage (see Appendix 2). These can be used as key points to make the whole process more sustainable. It has to be noted that technological support as well as technical and legal advice are needed in every stage of the flow sheet.

\section{Literature study}

In order to gain more information about the problem at hand, we performed a literature study. The full literature study with references to the documents used can be found in Appendix 3. It focuses mainly on the ecological aspect of this project. Based on the information gathered we made a comparison between the two techniques, using five parameters that are most frequently linked to advantages and disadvantages of both techniques. The main results of this study are summarized in Table 1. In the following paragraphs we briefly discuss the most important findings from classic beam trawling and electric pulse trawling with regard to the marine ecosystem.

Beam trawling uses a beam attached to the opening of the net to keep it from closing in the water. This beam allows the attachment of tickler chains to startle flatfish up from the seabed and into the nets. The net and tickler chains are dragged across the seabed and thereby cause damage to the seafloor, its inhabitants, 


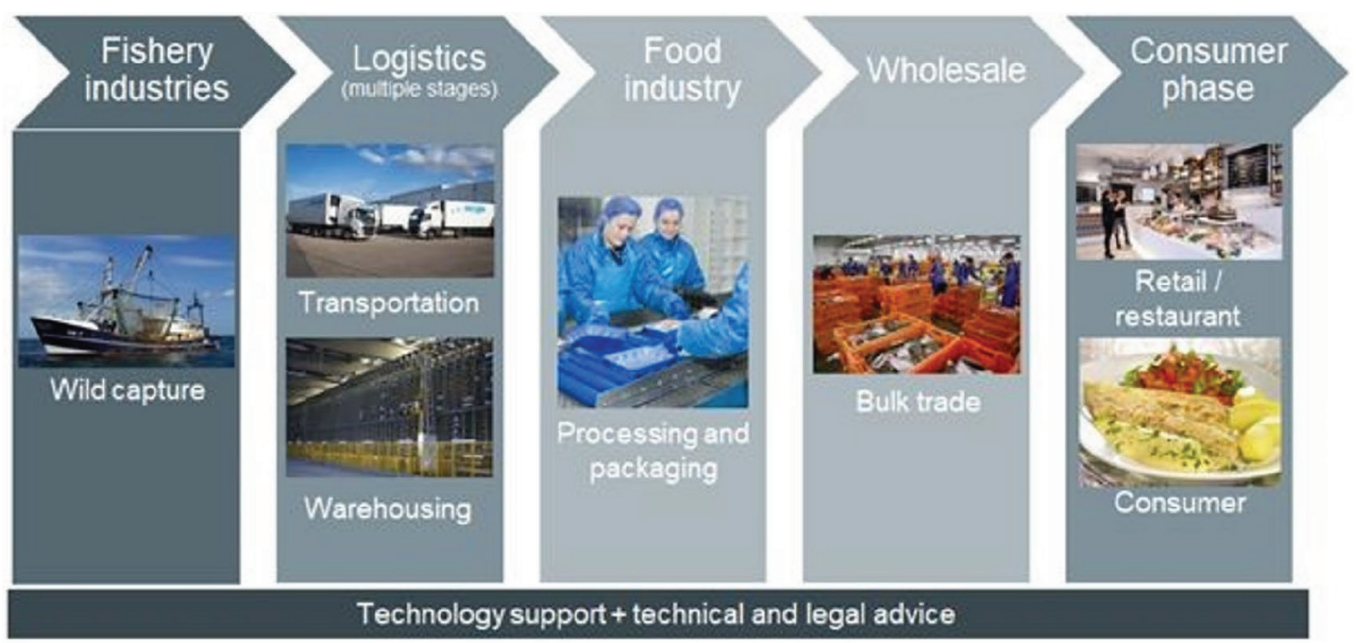

Figure 3. Stakeholders' flow sheet from sea to plate.

corals, and sponges. Due to the lack of selectivity of the net, non-target species can end up as bycatch. In addition, the resistance of the net against the seabed leads to high fuel consumption and the emission of combustion gases. In the case of electro trawling, the tickler chains used for classical beam trawling are replaced by electrodes that emit electric pulses. These pulses cause brief convulsions in the muscles of the fish residing in the seabed, causing them to rise up and get caught in the net. Because in this case only the surface part of the seabed is touched and no deep intrusion into it occurs, it is mainly flatfish that are caught and only a small fraction of other fish species.

Electro trawling has several advantages compared to classical beam trawling. It does not disturb the seabed to the same extent and therefore fewer creatures living on and in the seabed end up as bycatch. The ships also use less fuel because the pulse trawl is lighter and has less drag resistance. This results in fewer $\mathrm{CO}_{2}$ emissions and lower costs for fishermen. Also, the fish that are caught are of better quality because they have suffered less direct damage. However, electro trawling might have some disadvantages as well. The electric pulse can induce vertebral fractures in roundfish. This occurs in approximately $2 \%$ of the whiting and $9 \%$ of the cod. The electric pulses might also affect benthic invertebrates. However, it is believed that the electric pulse does not affect the mortality of benthic species. At last, it is hypothesized that the electric pulses might induce chemical reactions which release pollutants that are bound to sediment particles. Since 2009, EU member states have been allowed to use electro trawling in the southern part of the North Sea with up to $5 \%$ of their fleet. The Dutch intensively use and investigate electro trawling. Despite the fact that electric pulse trawling has disadvantages as well (see Table 1), it might be a sustainable alternative to the classical beam trawling.

\begin{tabular}{|l|l|l|}
\hline & Conventional trawling & Electro trawling \\
\hline Seabed disturbance & High & Low \\
\hline Direct injuries to fish & High & $\begin{array}{l}\text { Medium } \\
\text { (vertebral fractures) }\end{array}$ \\
\hline By-catch & $\begin{array}{l}\text { High } \\
\text { (only depends on type of nets) }\end{array}$ & $\begin{array}{l}\text { Low } \\
\text { (depends on pulse voltage and } \\
\text { frequency and type of nets) }\end{array}$ \\
\hline $\begin{array}{l}\text { Fuel consumption \& } \mathrm{CO}_{2} \\
\text { emissions }\end{array}$ & High & Low \\
\hline $\begin{array}{l}\text { Risk of damage to spawning } \\
\text { grounds }\end{array}$ & Yes & Potentially \\
\hline
\end{tabular}

Table 1. Comparison between the ecological effects of electro trawling and conventional trawling. 


\section{Interviews with stakeholders}

Apart from the ecological aspect, it is also important to have other insights into the topic. We therefore decided to interview three stakeholders: a spokesperson from the $\mathrm{EU}$, a representative from the NGO BLOOM, and professor Rijnsdorp from Wageningen University who is well-known in the electro trawling field. Unfortunately, we could not reach a spokesperson from the EU. The interviews with the BLOOM representative and with professor Rijnsdorp were finally done as phone calls.

Professor Rijnsdorp is investigating the effects of electro trawling on the marine ecosystem and is a profound supporter of this technique. He considers the European Parliament has taken a political decision based on emotions and not on scientific evidence. The NGO BLOOM aims to preserve all marine resources for future generations. It claims that electro trawling is destructive of the seabed ecosystem and that it is not selective. It also states that electro trawling is too effective and literally empties the oceans. However, it admits that classical beam trawling is a destructive technique 'as well'. Since we could not reach an EU spokesperson, we decided to analyze an EU document that includes all written explanations of the vote on January 16, 2018. ${ }^{[25]}$ Based on these explanations, we feel that the European Parliament voted against electro trawling because of a suspicious attitude toward pulse fishing. Arguments that are often encountered are that electro trawling is devastating for marine ecology and that it is unethical to electrocute fish. Additionally, it is often argued that there are too many unknowns related to this technique.

\section{Discussion}

Firstly, background information was gathered on the ecological, political, and economic aspects of trawling and pulse fishing, as well as on the concept of a Life Cycle Assessment (LCA). It showed, however, that comparing the two fishing techniques by using an LCA would be too specific and a too strictly exact-scientific approach, as a broader view of the problem was in fact aimed at.

While gathering background information, it was soon noticed that, even with different scientific backgrounds being present in the research team, there was still a lack of insight into several areas, such as the economic, political, and social sciences, which was deemed necessary to get to a more complete understanding of the problem and the views of the different stakeholders. Furthermore, difficulties regarding the large amount of information available and the very specific - not so general - nature of this information were experienced.

Based on the analysis presented above, it is not straightforward to come up with a perfect solution. During the process of gathering information and writing the report, we noticed that both fishery techniques have advantages and disadvantages, summarized in Table 1. The value that was concentrated on first was ecology. The technique of electro trawling seems very promising ecologically. With traditional beam trawling, the seabed is disturbed on such a large scale that ecosystems are seriously harmed and take a long time to recover. Yet, these ecosystems are important to keep fish stocks healthy. It is true that electro trawling will also carry risks for the ecosystems of seas and oceans, but hitherto there has been no clear evidence that electro trawling would reduce the resilience of certain species. Besides, bycatch is reduced by using electro trawling instead of bottom trawling. Either way, there are still challenges for all stakeholders in this process.

For fishery industries, it will be key that fish quotas are still respected. Electro trawling may be more efficient, and as a consequence quotas may be reached faster. Fishermen will have to spread their fishing efforts in both time and space, and in such a way that the quotas are not exceeded, since most of the positive effects of the technique will vanish if they are not respected. They will also have to make large investments in new gear, and this should maybe be funded by the government. At this moment, there are already large subsidies going to the fishery industry. Larger companies get bigger shares; small-scale fisheries get smaller shares. It might be desirable to work out an arrangement that makes sure the smallscale fisheries get their fair share of both the subsidies and the fishing quota.

Another stakeholder is the consumer, although the majority of the people may not care too much about how the fish is caught, and certainly not about the debate between beam trawling and electro trawling. Certainly, consumers can be critical, but this criticism focuses on aspects of fishery other than this one. For example, the differences between aquaculture and wild catch are much greater and could really divide 
opinion. From the scientific point of view the electro trawling technique seems to be preferred. It is motivating to see that advances in a field are actually appreciated if it is proven that a new method works and that apparently no large risks are involved. From a scientific perspective, it is then disappointing to see that, after so much time and work has been invested in a technique, it is now banned, even though there seem to be clear ecological benefits. This might be a challenge for NGOs gathering objective information on both techniques, i.e. if they indeed found that electro trawling is to be preferred, to then try to convince governmental instances that new technological advances like this one are worth a shot, and that it may not be a bad decision to invest money in it.

Also important is the socio-economic aspect. The team conducting this research has no expertise in this and we had to make an extra effort to understand it. An issue that was considered in some detail is the future of the fishermen themselves. If electro trawling were to be made completely legal for the whole catching quota, it is possible that the quota could be caught using fewer fishermen to do the job. In the first instance, this seems to be a huge problem because a lot of fishermen would lose their jobs. On the other hand, it is possible that some of them would not mind stopping fishing if they had the chance. Early retirement could be a more attractive solution for them. However, we did not find hard evidence that electro trawling is in fact more effective than beam trawling, so this problem might not be too big. Electro trawling might even be less efficient than beam trawling, but instead be more selective. This means that the share of the target species in the total catch will be higher. Nevertheless, some countries argue that electro trawling would deplete fish stocks faster. This is a bit confusing, since quotas still have to be respected, and bycatch and the share of immature fish caught are limited.

In conclusion, the technique of electro trawling seems to be more advantageous than traditional beam trawling for the reasons summed up above and in Table 1, and discussed more thoroughly in Appendix 3. However, more expertise from other sectors is still required. There are certainly things that were overlooked in this limited study. An economist and a social expert could help with the socio-economic part of this project, as the team lacks sufficient background in these matters. Cooperation with economists, social experts, and maybe even lawyers could pave the way to an integrated solution for the problem of sustainable fisheries.

\section{Conclusion}

Sustainable fishery is about finding fishery techniques which allow for ecological as well as socio-economic sustainability. It is supposed to minimize the damage to the marine ecosystem, respect quotas, and also give job security to the fishermen. Based on these ecological and socio-economic factors, a direct comparison was made between electric trawling and classical trawling techniques.

Because of the smaller amount of ecological damage done by electric trawling, it is considered to be ecologically the more sustainable fishing technique for flatfish. However, it provides advantages only to large corporations and seems to cause financial disadvantage to small-scale fisheries. This then poses an important socio-economic problem.

Despite the ecological advantage of the electric trawling technique over classical trawling the European Parliament decided to vote for a ban on the former. Criticism of the lack of sufficient scientific evidence for the safety of the technique and socio-economic and politically funded arguments was the motive of the European Parliament in banning electric pulse fishing.

The Bloom association also considers the ban on electric trawling a good solution. In fact, Bloom considers both the electric trawling and the classical trawling methods to be dangerous for the marine ecosystem and states that both should be banned as fishing techniques for plaice.

The big question here is: Is a compromise possible? There are different opinions within the European Parliament itself while, in addition, the many other stakeholders involved do not agree. Reaching a compromise within and between all these bodies might bring an acceptable solution. A possible way of finding a solution might be by further discussions among all parties involved. A solution to this problem has to take into account ecological as well as socio-economic sustainability, thereby including preventing the loss of fishermen's jobs.

\section{Acknowledgments}

We would also like to thank Professor Adriaan Rijnsdorp from Wageningen University and Research and 
Mrs. Laetitia Bisiaux from BLOOM association for their time and for sharing their opinions on this subject.

\section{Appendix}

\section{Distribution of the stakeholders according to legitimacy, urgency, and power}

The distribution of stakeholders according to their power and the role they play in the problem as described in the introduction and analysis can be (more or less) rationalized using the definitions of different types of stakeholder (e.g. dangerous stakeholder, dormant stakeholder, etc.), proposed by Mitchell et al. (1). The types of stakeholders are characterized by three factors, which overlap in a Venn-type diagram (Fig. 2). Each surface in the diagram represents a stakeholder. Urgency can be defined as the degree to which a stakeholder demands immediate action. Legitimacy is defined as the perception that actions of the stakeholder in question are desirable, proper, or appropriate according to society, within the system of norms, values, etc. Power is the relationship within which one stakeholder can get another stakeholder to do something that he/she would not otherwise have done.

It should be noted that there is more than one possibility for filling the scheme in Fig. 2. For example, the consumer and the EU (i.e. the government) can be interchanged since it is desirable that the government makes laws to protect the marine ecosystem, while consumers (voters) have the power to change the power balance in the government through elections, and thus can let the new government do something the old government would otherwise not have done. Also, through general opinion and purchasing decisions, the consumer has great influence on the food and fishing industries. However, we argue that the government in fact is the dormant stakeholder (possesses only power) since it directly imposes the rules, thus letting the fishing and food industries do something they would otherwise not have done. The government cannot act until a critical mass in the group of voters/consumers decides that action is needed. The consumer can take action through manifestation, writing, NGOs' actions, and voting, thus appropriately choosing the course of the government. Defining the demanding stakeholder (urgency) is easier. Here, it is clear that the main actor is the marine ecology and the environment itself. It does not have a voice itself, so it is powerless and needs NGOs, which are considered to be 'dangerous stakeholders', since they combine urgency and power. Besides, the latter often lack the legitimacy factor, since there is initially always resistance against the change they want to set in motion. As to the dependent stakeholder, which has both a legitimate and an urgent claim but no power, the 'future generations' were selected here since they are voiceless but are effectively to be taken into account as they are the ones who invoke some the norms and values in the debate: "We have to preserve the resources for our children." Obviously, the food and fishing industries are the dominant stakeholder, since they are able to directly change the course of their actions, having an immediate impact on the matter in question. For example, they can decide to focus on sustainable trawling because they want consumers to have a positive view of them so that they will buy their products more often. Finally, there is the definitive stakeholder, who comes into all of the categories. In this case, we chose the fishermen. They have the power to change the ways of the fishing industries, since they can go on strike or demand change via unions. Generally, we agree that fishermen impose their values and norms on the debate (legitimacy), since they are the experts and most involved stakeholder in this matter (fishing is their job, their life). Finally, fishermen also see that the way the fishing industry organizes the fishing activity has to change if they want to keep their jobs: no fish means no fishermen.

\section{Life cycle inventory}

\begin{tabular}{|l|l|l|}
\hline Stakeholder & Input & Output \\
\hline Fishery industries & - Energy & - Caught fish \\
& - Fishing gear & - Bycatch \\
Fishermen & - Boat - Fuel & - Scrap metal \\
& - Staff & - Plastic nets \\
\hline
\end{tabular}




\begin{tabular}{|c|c|c|}
\hline & & $\begin{array}{l}\text { - Combustion gasses } \\
\quad\left(\mathrm{CO}_{2}, \mathrm{NO}_{x}, \mathrm{SO}_{2}\right) \\
\text { - Marine ecology damage } \\
\text { - } \mathrm{GHG} \text { and nuclear waste } \\
\text { - (indirect from energy production) }\end{array}$ \\
\hline $\begin{array}{l}\text { Logistics } \\
\text { (transport) } \\
\text { (warehousing) } \\
\text { (at multiple stages) }\end{array}$ & $\begin{array}{l}\text { - Energy } \\
\text { - Vehicles } \\
\text { - Fuel } \\
\text { - Buildings } \\
\text { - Packaging }\end{array}$ & $\begin{array}{l}\text { - Combustion gasses } \\
\text { - Halogenated hydrocarbons } \\
\quad \text { (from cooling) } \\
\text { - Scrap metal } \\
\text { - Plastics } \\
\text { - Building waste } \\
\text { - GHGs and nuclear waste } \\
\text { (indirect from energy production) }\end{array}$ \\
\hline $\begin{array}{l}\text { Food industry } \\
\text { (processing) } \\
\text { (packaging) }\end{array}$ & $\begin{array}{l}\text { - Energy } \\
\text { - Packaging } \\
\text { - Machinery } \\
\text { - Other ingredients }\end{array}$ & $\begin{array}{l}\text { - Semi-manufactured products/packaged food } \\
\text { - Food waste } \\
\text { - Waste from packaging } \\
\text { - GHGs and nuclear waste } \\
\quad \text { (indirect from energy production) }\end{array}$ \\
\hline Wholesale & $\begin{array}{l}\text { - Energy } \\
\text { - Buildings } \\
\text { - Vehicles }\end{array}$ & $\begin{array}{l}\text { - Combustion gasses } \\
\text { - Waste from building material } \\
\text { - Scrap metals } \\
\text { - Plastics } \\
\text { - GHGs and nuclear waste } \\
\quad \text { (indirect from energy production) }\end{array}$ \\
\hline Consumer phase & $\begin{array}{l}\text { - Energy } \\
\text { - Natural gas } \\
\text { - Refrigerators, freezers } \\
\text { - Kitchen tools } \\
\text { - Other ingredients }\end{array}$ & $\begin{array}{l}\text { - Prepared Food } \\
\text { - Food waste } \\
\text { - Human waste } \\
\text { - Packaging waste } \\
\text { - GHGs } \\
\text { - Halogenated hydrocarbons } \\
\text { (from cooling) } \\
\text { - GHGs and nuclear waste } \\
\text { (indirect from energy production) }\end{array}$ \\
\hline
\end{tabular}

\section{Literature study}

\section{a) North Sea and plaice ecology (Refs. 2, 3)}

The North Sea is a marginal sea of the Atlantic Ocean located between Great Britain, Scandinavia, Germany, the Netherlands, Belgium, and France. It has a shallow (<50 m) south-eastern part and a much deeper (50-100 $\mathrm{m})$ central part that is situated to the north of the British coast. the central northern part of the shelf goes down to $200 \mathrm{~m}$. The maximum depth is reached along the Norwegian coast, where the Skagerrak can be up to $500 \mathrm{~m}$ deep. Water circulation in the North Sea is mostly represented by a counter-clockwise gyre, driven mainly by the wind. This pattern may sometimes be reversed or split into two gyres in the north and in the south. These currents may have an influence on the transport of larvae and eggs of multiple species in the North Sea. The temperature and salinity of the North Sea are influenced by the North Atlantic Oscillation (NAO), by the movement of water between these two ocean bodies, and by the ocean-atmosphere heat exchange. The temperature of the water varies from $6^{\circ} \mathrm{C}$ in winter to $17^{\circ} \mathrm{C}$ in summer, while the salinity of the water is typically about 34-35 g of salt per liter, being lower around freshwater inflows. Like many other regions in the world, the North Sea is also influenced by climate change, and this has already started on the lowest level of the food chain: the plankton community. The plankton community is shifting towards warmer water species, and this is clearly associated with a decline in fish reproduction, especially cod. The zooplankton is of critical importance for the food web in the North Sea, as 
well as for fishery yields and the sensitivity of the community to further climate change. The next level in the food chain is the larger benthic invertebrates. Their community composition varies with sea depth and sediment type and is also affected by temperature and trawling intensity. Beam trawling used in plaice fishing alters biomass, production, size structure, and diversity of benthic communities, reduces the growth of the benthic invertebrates and increases mortality. This may eventually lead to a food shortage for fish, the next level of the food chain. The dominating pelagic fish species is herring (Clupea harengus) and the main flatfish species are the common dab (Limanda limanda), plaice (Pleuronectes platessa), and sole (Solea vulgaris). Due to overexploitation, fish mortality has increased, the mean size of individuals in the community has decreased, and the abundance of smaller species has increased. The major forage fish species is the sandeel (Ammodytes marinus) and is an essential component of the diet of piscivorous fish species but also of the puffin, but has declined over the last 25 years. This decline will have serious implications for these piscivorous fish species, but also for birds and marine mammals.

Although a lot of information is available already on the processes happening in the North Sea, there is still need for further research, especially in the fields of community ecology, temperature preferences of organisms on all food levels, implications of depleted populations, and measures for population fecundity.

The fish species focused on in this project and a popular fish in North Sea fisheries is the European plaice (Pleuronectes platessa). It is a common flatfish and occurs on muddy or sandy bottoms from the western Mediterranean and along all European coasts. The upper side of the plaice is dark green to brown with orange spots, making it conspicuous to predators. The side of the plaice that is in contact with the soil is pale white. Both eyes are located on the right side of the body. Another remarkable characteristic of the species is the curved lateral line. Plaice is mostly active at night and is a generalist: it feeds on polychaetes (worms) and bivalve molluscs.

Plaice has a rather complex life cycle with different life stages occurring in different, specific habitats. Spawning happens in deep water from January to June, laid eggs and developed larvae are pelagic and drift with the current. Although they cannot resist these currents, they can change their vertical position in the water column to enter favorable currents until they arrive at a suitable habitat for metamorphosis. Metamorphosis takes place at nursery grounds in estuaries and along sandy coasts. In the first years of their lives, the juveniles spend their time in these nurseries. As they grow older, they move to deeper water. Age at maturity for males is $2-3$ years and for females $4-5$ years. Adult plaice migrate between feeding areas and spawning grounds and can reach ages up to 30 years. During the whole lifespan, sandy bottoms remain the preferred sediment type for the species.

\section{b) Classical trawling (Ref. 4)}

Some information on trawling and its effect on the environment will be given here. Trawling can be divided into two kinds: midwater and bottom trawling. In midwater trawling (also known as pelagic trawling) a large funnel-shaped net is towed by a fishing vessel through a water column far enough from the sea bottom. Bottom trawling on the other hand is a fishing technique where the net is dragged along or close to the sea floor. We will focus on the latter as it is more relevant to our case study regarding fishing for flatfish, which reside on the ocean floor. There are several different trawling methods. Beam trawling is a method where a beam is placed in the opening of the net to keep it from closing. This beam also allows the attachment of several tickler chains to the frame of the net. These tickler chains startle the creatures burrowed in the seabed, causing them to rise so that they can be caught in the net. Another well-known method called otter trawling uses so-called "otter boards", attached to both sides of the net, to keep the mouth of the net open. These trawling methods can be used for both midwater and bottom trawling.

As the net is towed across the seabed, it causes a large amount of damage to the seafloor and its inhabitants. Trawlers can greatly reduce the textural complexity of the seabed and plow deep furrows in it. A distinction can be drawn between immediate and long-term effects. How large these effects are depend greatly on the amount of contact with the seabed, the depth, the nature of the seabed, and the strength of the currents. In areas where currents are abundant, the effects caused by the displacement of sediment are short-lived compared to places like the deep ocean, where there is very little water movement. Fortunately, in many European Union waters, including 
the North Sea, bottom trawling is not allowed at a depth below 800 meters (10).

During trawling, macrobenthos, which are bottom dwellers that are visible to the naked eye, are removed. Some of these macrobenthos cannot recover, while other species soon recolonize. In some places such as the Wadden Sea and the Kattegat, there has been a noticeable increase in some populations, while at the same time a reduction has occurred in others (6). Whether this is a result of trawling alone is difficult to determine, as natural fluctuations and other changes such as pollution can also influence the growth or decline of the populations. Some field studies suggest that the abundance of macrobenthic species (epifaunal and infaunal) is reduced by trawling, and that large species are generally more vulnerable than smaller ones (8). This causes a greater prevalence of small infaunal species in the trawled communities. The increase in the production of smaller infauna, however, seems rather small in relation to the losses in overall community production, caused by the reduction in the population of larger fish. Small meiofaunal species, marine creatures smaller than macrofauna and bigger than microfauna, seem to be relatively unaffected by trawling, and this might be because they are resuspended by the trawl rather than crushed, or because they have fast generation times (5). Bottom trawling also causes the destruction of many deep-sea corals and sponges, which are the habitat of a large amount of marine life. Between 1997 and 1999 the destruction was of the order of one million pounds of corals and sponges in Alaskan waters alone (7).

Another major ecological threat is the amount of "bycatch". "Bycatch" is a term used for the marine species that are unintentionally caught while fishing for a specific target species or target size. Because of the lack of selectivity of the trawl net, trawling catches a large number and diversity of non-target species. Many of those fish end up being discarded because they lack commercial value, because of the cost involving in landing fish, or because of the lack of storage on the fishing vessel.

Shrimp trawling has one of the highest discard/catch ratios of the fisheries, which ranges from 3:1 to 15:1. This ratio is of course dependent on the area, season, and target species. Data from the 1980 s and early 1990s revealed that commercial bottom trawling contributed about 27 million tons of discards. An analysis by
FAO based on data from 1992 to 2002 estimated that the discard rate was $8 \%$ of the total catch (9).

When towing a large net across the seabed, the fishing boat experiences a large amount of resistance from the ground. Therefore, a large amount of fuel is needed to move the trawler forward. When looking at the data concerning the fuel combustion of the Swedish cod fishery in 1999(5) one notices that the emissions $\left(\mathrm{HC}, \mathrm{NO}_{x}, \mathrm{CO}, \mathrm{SO}_{x}\right.$ and $\left.\mathrm{CO}\right)$ from trawling are much greater than from e.g. gillnet fishing, another method that is often used by Swedish fishermen to fish for cod. The large fuel consumption is not helped by the large fuel subsidies given to fisheries. These subsidies give an economical advantage to trawlers. Their large fuel consumption, on the other hand, makes them very sensitive to fuel price increases. Pair trawling, where the trawl net is towed between two fishing vessels, also seems to give lower emission levels than regular trawling. A big disadvantage of this method, however, is the large amount of bycatch. This disadvantage of pair trawling also resulted in the prohibition of pair trawling for bass by UK vessels in UK territorial waters.

\section{c) Electro trawling as an alternative}

Since beam trawling is associated with several disadvantages such as seabed disturbance and high fuel consumption, alternative and 'more sustainable' methods of catching flatfish have been explored since the 1970s (11). Electro trawling, using electrical stimulation to catch fish, is the most recent development in the flatfish fishery. Here, the tickler chains used for classical beam trawling are replaced by electrodes that emit electric pulses. These pulses cause brief convulsions in the muscles of the fish, causing them to rise up from the seabed and get caught in the net.

Currently, the technique is largely banned in Europe. However, since 2009 member states have been able to obtain an exemption to use electro trawling in the southern part of the North Sea for up to $5 \%$ of their fleet (12). Within the EU, it is the Dutch who intensively use electro trawling with a total of 84 exemptions in 2014 (11).

Based on scientific literature, electro trawling indeed seems to possess several advantages compared to classical beam trawling. First of all, electro trawling does not disturb the seabed to the same extent as classical beam trawling, and therefore fewer creatures 
living on the seabed end up as bycatch. The ships also use less fuel because the pulse trawl is lighter and has less drag resistance, resulting in less $\mathrm{CO}_{2}$ emissions and lower costs for fishermen. Also, the fish that are caught are of a better quality because they have suffered less direct damage (12).

Unfortunately, electro trawling also has detrimental effects on marine organisms and the marine ecosystem. There is evidence that the cramp evoked by the electric pulse induces vertebral fractures and associated haemorrhages in roundfish such as cod and whiting. Based on a comparative fishing experiment, it is estimated that vertebral fractures are induced in $9 \%$ of the cod and in $2 \%$ of the whiting (13). It is clear that sensitivity to the electric pulse and the incidence of vertebral fractures differ between different fish species. According to De Haan et al., the probability of developing fractures increases with field strength and decreases with frequency and body size(14). The electric pulses also affect benthic invertebrates, which show responses such as closing their shells, withdrawing into their shell or showing a tail flip response. However, some benthic species did not show a visible response, and it is suggested that the electric pulse does not affect the mortality of benthic species as compared to a control group (11). Although no studies have yet addressed this question, it is hypothesized that the electric pulses might induce chemical reactions releasing pollutants that are bound to sediment particles.

\section{d) Comparison between conventional trawling and electro trawling Ecological (Refs. 15-19)}

Some more explanation is obviously necessary for Table 1. For every parameter, a short discussion and some examples from the literature will be given.

In the case of seabed disturbance, it is clear that electro trawling offers the best advantages. In electro trawling there is often no contact with the seabed. Only in flatfish fishing is a footrope (rope with electrodes on it) still in contact with the bottom. This rope is much lighter than the tickler chains often used in conventional (beam) trawling which penetrate the seabed more intensely, to a depth of $8 \mathrm{~cm}$ on average, thereby destroying the local ecology and damaging fish and benthic invertebrates.

The reduced contact with the seabed in the case of electro trawling also has another major advantage: less fuel is consumed due to the smaller friction and because the electro trawling equipment is lighter compared to conventional trawls of a similar size. For conventional trawling, about 2.5 to 4 liters of fuel is needed per kilogram of fish. About $65 \%$ of the fuel is used in dragging the trawl over the seabed and $30 \%$ of the total fuel is lost to the resistance of the tickler chains on the bottom. Studies have shown that electro trawling consumes up to $50 \%$ less fuel.

Another consequence of direct contact with the seabed is possible damage to the sea life which thrives on the bottom. Spawning grounds (e.g. in muddy estuaries) can also get damaged by passing trawlers. In the classical trawling technique using mechanical excitation of the fish, the damage to the life forms is quite obvious. Here, the trawl, or at least the tickler chains, plows through the sediment, often hitting marine life forms that were not the original target. In electro trawling, many studies have been performed on the possible damage to other fish and the benthic invertebrates in the marine environment, but knowledge of the harmful effects on marine organisms is still scarce. The opponents of electro trawling claim this to be the main reason why it should be banned. Of course, they also acknowledge the harmful effects of conventional trawling, and therefore prefer to limit any activity of this type. Other, less damaging ways to catch flatfish such as plaice can be applied as well. One could think of aquaculture as a possibility, but experimental work in the United Kingdom in the 1940s showed that this would not be economically viable due to the expensive feed and the slow growth rate of the plaice. Diseases were also a problem in aquaculture plaice. Although there are not many alternatives, several countries have actually already banned trawl gear entirely (e.g. Belize).

Several investigations of various fish species and invertebrates showed that the damage caused to other organisms by electro fishing is in fact rather limited. Cod has been studied the most. It was concluded that, while $50-70 \%$ of adult cod exposed to highly intense electrical fields showed spinal injuries, none of the juvenile cod were affected. In dogfish, a species that relies on electroreceptors for finding its prey, no injuries and no deviating feeding patterns were found. Benthic invertebrates did not show any effects or reactions to electrical pulses that were twice as intense and lasted 8 times longer than those used in conventional electro trawling. Van Marlen et al. 
(2009) found similar results and concluded that "it is ... plausible that the effects of pulse beam trawling, ..., are far smaller than the effects of conventional beam trawling". Besides this conclusion, quite some attention has also been paid to the effect of pre-set parameters, such as the voltage, frequency, and duration of the electric pulses. These can be optimized to get the most efficient catch results of the target species with the least amount of damage to other species, since the excitation/injury thresholds for each species are different. An important side-remark to make is that these studies were all investigating short-term effects. Long-term effects and repeated exposure might be interesting as well in order to estimate the real impact of this kind of fishery.

A last factor to consider is the selectivity of these fishery techniques. Apart from fuel consumption, this is the only technique for which data are available to quantify the respective impacts. The quantification is usually given as mass of bycatch (non-target species or non-saleable target fish that are caught) relative to the total mass of the landing or the total mass of the target species. Through improvement of the nets and new legislation making discarding bycatch illegal (EU 2013), the annual amount of discards has steadily dropped to pre-1950s levels (less than 10 million tons per year). The question of what to do with the bycatch is important, and still under investigation. Some nonmarketable species, such as starfish, still pose a problem.

According to Zeller et al. (2018), active bottomcontact gears (i.e. conventional trawling) are one of the most widespread large-scale types of fishing gear and are known to produce the highest amount of discard of any fishing gear. This is in contrast with electro trawling, which has very high selectivity because the pulses can be fine-tuned in such a way that only the target species is affected. Of course, both in conventional trawling and electro trawling the design of the nets plays a crucial role. (The shape and size of the holes in the nets help to 'select' the right species. Also, industrial fisheries are the main contributor $(93 \%)$ to discards, while small-scale fishers typically discard very little.)

\section{Socio-economic (Refs. 20-24)}

A constant demand for fish in general and for plaice (or flatfish) in particular poses the need for the use of more effective and sustainable methods of fishing in order to meet present and future demands. The two fishing techniques, the classic trawling and the electric pulse techniques, show a variation in the catch efficiency with respect to the type of fish under consideration. This can be seen by the higher catch efficiency of the pulse trawling technique for sole and its lower catch efficiency for plaice and other species.

However; in 2011 the successful implementation of the pulse trawl technique in the Dutch flatfish fishery showed a $21 \%$ and $28 \%$ reduction in the catch rate per hour for marketable-sized sole and plaice respectively. This was attributed to the lower towing speed and hence the smaller surface area covered per hour of fishing. At the same time, the discarded bycatch catch rate for the pulse trawl was reduced by $67 \%$. Despite the lower catch rate, electro trawling is still more efficient due to high selectivity for a single kind of fish (e.g. plaice). Also, the size selectivity for plaice (only adult species) suggests that the pulse trawl is more selective in catching marketable-sized flatfish. The choice of pulse trawling over classic trawling for catching plaice is thus made mainly for ecological reasons, but other social factors will give reasons for using the classical trawl technique and hence the banning of the pulse trawl technique by the European Union.

The high cost of pulse trawl equipment, as well as the high cost of maintenance, poses a problem for smallscale fishermen who will find it difficult to finance the activity. This might lead to those fishermen losing their jobs. However, the effect of pulse trawling on the jobs market in general is not very certain.

Fuel consumption per kilogram of fish caught should also be taken into consideration. The pulse trawling method uses less fuel, thereby corresponding to a lower fuel consumption per kilogram of fish caught. This leads to a decrease in the emission of $\mathrm{CO}_{2}$ and also to a decrease in fish prices.

Despite the obvious ecological benefits of the pulse technique over the classical trawling technique, the European Union decided to place a ban on the pulse trawl technique (25). This decision can be seen to have been made for socio-political and economic reasons. In certain countries (France, UK, etc.), only small-scale traditional plaice fisheries exist, which suffer as a result of the Dutch fishery industries, which have a long tradition of fishing for plaice on a grand scale. The decision of these countries to back the 
prohibition on electro trawling, used by almost half the Dutch fleet, can probably be seen as economic protectionism. However, it also has a legal basis, since the Dutch were allowed to apply electro trawling to only a limited percentage of their fleet $(5 \%)$ under the cover of scientific research. However, at present, after gaining concessions from the EU Commission over the last few years, their fleet has exceeded the 5\% limit and is no longer used just for gathering scientific data, but is applied to the large-scale industrial fishing of flatfish.

\section{References}

1. Mitchell, R. K., Wood, D. J., Agle, B. Toward a Theory of Stakeholder Identification and Salience: Defining the Principle of Who and What Really Counts. Acad. Manag. Rev. 1997, 22 (4), 853-886.

2. Freyhof, J. 2014. Pleuronectes platessa. The IUCN Red List of Threatened Species 2014: e.T135690 A50018800. Available from: http://dx.doi.org/10.2305/ IUCN.UK.2014-1.RLTS.T135690A50018800.en.

3. International Council for the Exploration of the Sea. Book 6 North Sea; Copenhagen, 2008.

4. National Research Council. 2002. Effects of Trawling and Dredging on Seafloor Habitat. Washington, DC: The National Academies Press.

5. Ziegler F., Hansson P. A., Emissions from fuel combustion in Swedish cod fishery. Journal of Cleaner Production. 11, 303-314 (2003).

6. Jones J. B., Environmental impact of trawling on the seabed: A review. New Zealand Journal of Marine and Freshwater Research. 26, 59-67 (1992).

7. Lewison R. L., Crowder L. B., Read A. J., Freeman S. A.,Understanding impacts of fisheries bycatch on marine megafauna. Trends in Ecology and Evolution. 19 (2004), pp. 598-604.

8. Schratzberger M., Dinmore T. A., Jennings S., Impacts of trawling on the diversity, biomass and structure of meiofauna assemblages. Marine Biology. 140, 83-93 (2002).

9. Kumar A. B., Deepthi G. R., Trawling and by-catch: implications on marine Trawling and by-catch: Implications on marine ecosystem. Current Science. 90 (2006).

10. Regulation (EU) 2016/2336 of the european parliament and of the council of 14 December 2016.

11. Rijnsdorp A, de Haan D, Smith S, Strietman WJ. Pulse fishing and its effects on the marine ecosystem and fisheries An update of the scientific knowledge. Wageningen Univ C117/16 [Internet]. 2016;30. Available from: https://doi.org/10.18174/405708.
12. Louwerens, T. Is pulse fishing the future? Resource 11(2017)18, p. 12-15, May 11, 2017. http://edepot. wur.nl/438358.

13. Van Marlen B, Wiegerinck JAM, van Os-Koomen E, van Barneveld E. Catch comparison of flatfish pulse trawls and a tickler chain beam trawl. Fish Res [Internet]. Elsevier B.V.; 2014;151:57-69. Available from: http://dx.doi.org/10.1016/j.fishres.2013.11.007.

14. Haan D, Fosseidengen JE, Fjelldal PG, Burggraaf D, Rijnsdorp AD. Pulse trawl fishing: characteristics of the electrical stimulation and the effect on behaviour and injuries of Atlantic cod (Gadus morhua). 2014;73(March):1557-69.

15. Soetaert, M., Decostere, A., Polet, H., Verschueren, B., Chiers, K. Electro trawling: A Promising Alternative Fishing Technique Warranting Further Exploration. Fish Fish. 2015, 16 (1), 104-124.

16. Zeller, D., Cashion, T., Palomares, M., Pauly, D. Global Marine Fisheries Discards: A Synthesis of Reconstructed Data. Fish Fish. 2018, 19 (1), 30-39.

17. Rijnsdorp, A., de Haan, D., Smith, S., Strietman, W. J. Pulse Fishing and Its Effects on the Marine Ecosystem and Fisheries, An Update of the Scientific Knowledge. Wageningen Univ. C117/16 2016, 30.

18. Batsleer, J., Rijnsdorp, A. D., Hamon, K. G., van Overzee, H. M. J., Poos, J. J. Mixed Fisheries Management: Is the Ban on Discarding Likely to Promote More Selective and Fuel Efficient Fishing in the Dutch Flatfish Fishery? Fish. Res. 2016, 174, 118-128.

19. Iversen, E.S., Hale, K.K., Aquaculture Sourcebook: A Guide to North American Species. New York, 1992.

20. O'Neill, F. G., and Ivanović, A. 2016. The physical impact of towed demersal fishing gears on soft sediments. ICES Journal of Marine Science: Journal du Conseil, 73: i5-i14.

21. Paschen, M., Richter, U., and Kopnick, W. 2000. Trawl penetration in the seabed (TRAPESE). Final Report EC-Study Contract No 96-006. University of Rostock, Rostock, Germany: 150.

22. Van Marlen, B., Bergman, M., Groenewold, S., and Fonds, M. 2001. Research on diminishing impact in demersal trawling-The experiments in The Netherlands. ICES CM2001/R:09: 54.

23. Van Marlen, B., van de Vis, H., de Haan, D., Burggraaf, D., van der Heul, J, and Terlouw, A. 2007. The effect of pulse stimulation on biota-Research in relation to ICES advice-Progress report with preliminary results. IMARES Report number C098/07. 24 pp.

24. Van Marlen, B., de Haan, D., van Gool, A., Burggraaf, D. 2009. The effect of pulse stimulation on marine biota - Research in relation to ICES advice - Progress report on the effects on benthic invertebrates. IMARES Report number C103/09. 53 pp. 
25. EU Parliament, Written explanations of vote. Conservation of fishery resources and protection of marine ecosystems through technical measures (A8-0381/2017 - Gabriel Mato), January 16, 2018, 75-116
26. Zander, K., and Feucht, Y. 2018. Who is Prepared to Pay for Sustainable Fish? Evidence from a Transnational Consumer Survey in Europe. Proceedings in System Dynamics and Innovation in Food Networks. DOI: http://dx.doi.org/10.18461/pfsd.2018.1806. 